\title{
Fuel bunker management strategies within sustainable container shipping operation considering disruption and recovery policies
}

\begin{abstract}
The paper endeavours to explore the sustainable container shipping problem considering fuel bunker management and provide adequate recovery policies for countering disruption within maritime transportation. The research work addresses the environmental concerns related to fuel consumption and carbon emission within shipping operations and simultaneously presents strategies for countering disruption within maritime transportation domain. Several researches addressed bunker fuel management strategies but overlooked the need for integrating it with shipping operations. The paper aims to bridge this research gap by proposing a novel mathematical model and presenting a heuristic procedure combined with variable neighborhood search algorithm for maximizing the shipping company's profitability while addressing the vessel routing and scheduling decisions, container loading and unloading operations, selection of bunkering ports and determining bunkered amount for heavy fuel oil and marine diesel oil. Recovery strategies such as port swapping and rescheduling of vessel route are considered to deal with disruptions related to weather adversities. An illustrative example is presented depicting the realistic scenario and providing results associated with ship routes, vessel speed, bunkering ports, bunkered amounts, fuel consumed by the vessel on each sailing leg, arrival and departure time of the ships, etc. Insights obtained from the analysis, performed based on the fuel price, ship's bunkering capacity, adverse weather conditions on various routes, port closure, carbon tax and fuel consumption provide useful information for shipping company managers. Managerial implications are presented with regard to the impact of fuel prices and carbon tax on shipping operation from the perspective of overall operational cost. Moreover, the results provide important policy insights for shipping company managers in terms of possessing alternate vessel route options for normal scenario and disrupted scenarios including weather adversities on sailing leg or port closure.
\end{abstract}

Keywords: Maritime Transportation, Bunker Fuel Management, Bunkering Port, Vessel Speed, Bunker Fuel Price, Disruption within Shipping Logistics, Variable Neighborhood Search 


\section{MANAGERIAL RELEVANCE STATEMENT}

The research work presented in the paper will help the shipping company managers in maximizing the overall profit while trying to design the vessel route and schedule and also determining the bunkering port and bunkering amount. Moreover, the research work would also assist the shipping company managers in addressing the environmental concerns by reducing the carbon emission while adopting slow steaming and carbon tax policies and considering bunker fuel management strategies for lowering the fuel consumption. Moreover, the research also provides enough information to the shipping company managers in dealing with disruption related issues such as weather adversities within maritime transportation by adopting adequate recovery strategies such as port swapping and rescheduling of vessel route. The research work aims to propose a mathematical model and present a novel heuristics method for addressing different ship operation such vessel routing and scheduling, container loading and unloading, bunker fuel management strategies and recovery policies for countering disruptions. The analysis obtained out of the extensive computational experiments provide important organizational, practical and policy insights on (1) the impact of carbon tax and fuel prices on shipping operation, (2) the relationship between the vessel route design and bunker fuel management strategy, and (3) the effect of adverse weather conditions on various routes and making informed and timely decisions for countering disruptions.

\section{Introduction}

Maritime logistic is the primary mode of container transportation as it efficiently carries out the international trade between multiple ports. Shipping logistic accounts for 9.8 billion tons of seaborne trade in 2014 and global containerized trade increased by 5.3\% and reached 171 million TEUs in 2014 [1]. From 1990 to 2010, container trade expanded at the rate of 8.2\% per year due to several reasons such as increased level of global trade volume, economic globalization, efficient container handling facilities at the ports, etc. [2]. Containerships are preferred due to low cost, reduce damage, pilferage and reliable schedules. Although, increasing level of trade leads to a significant rise in carbon dioxide emission and container vessels contributed around 205 million tons of $\mathrm{CO}_{2}$ in 2012, making it the highest contributor in international shipping [3]. International Maritime Organization reported that global $\mathrm{CO}_{2}$ emissions reached to 36 billion 
tons in 2013 and immediate actions are required to mitigate the emission growth [1]. The rise in bunker price and an increase in fuel consumption emphasize the need of employing certain strategies for reducing the fuel cost incurred by the shipping companies. Therefore, considering the motivation stated above, it is essential to investigate the possible ways of reducing carbon emission and determining ideal bunker fuel management strategies while dealing with sustainable container shipping operation.

\subsection{Slow Steaming Strategy and Bunker Fuel Management}

In 2009, due to the financial crisis and sudden drop in international trade lead to the implementation of the slow steaming policy for dealing with the rise of fuel price and increase in $\mathrm{CO}_{2}$ emission [3]. De et al. [4] stated about the slow steaming strategy (slow steaming is the practice of operating container ships at significantly less than their maximum speed) as the possible operational measure for reducing the fuel consumption and thereby minimizing the fuel cost of the shipping company. Maersk Line is the earliest international shipping company which implemented the slow steaming strategy and enjoyed a considerable success by saving $22 \%$ of bunker fuel (bunker fuel is typically any type of fuel used aboard ships) and reducing carbon emission and fuel consumption [5]. As the revenue generated in transporting a container is much higher than the bulk cargo, hence the shipping companies tend to speed-up their container-ships for reducing the delay in delivering of the containers to their destination. As a result, the container-ship burns more fuel compared to other vessel types like cargo ships or oil tankers and thereby incurring higher fuel cost. It is essential for the shipping companies to efficiently manage the bunker fuel as the fuel cost constitutes about three-quarters of the total operating cost of the container-ships when the bunker fuel price is around 500 USD [6]. Xia et al. [7] addressed a problem of fleet deployment combined with slow steaming policy and cargo allocation for maximizing the profits, yet overlooking the importance of estimating fuel bunkering cost in the maritime transportation domain. The bunker fuel prices at different ports have significant differences, and it may affect the total fuel cost of the shipping company. Therefore, selection of bunkering ports and the amount of fuel to be bunkered remains one of the important decisions which depend on the varying bunker fuel price associated with different ports. Besbes et al. [8] dealt with a joint route selection and refueling problem in the domain of maritime transportation. The problem emphasized on the fact that increasing the profit margin requires lowering of the bunkering cost over a given ship route subject to limited vessel bunker capacities and changing 
fuel prices at different ports. Majority of the earlier research work considered that the order of the port visits for every ship is known beforehand. Although, the designing of the vessel route need to be performed along with the selection of the bunkering ports, as the ports with lower bunker fuel price are the preferred bunkering options because it helps to reduce the overall fuel bunkering cost substantially [9].

\subsection{Disruptions within Maritime Transportation}

Apart from bunker fuel consumption and carbon emission, the shipping company also need to look into possible recovery solutions for dealing with various disruptions related uncertainties occurring in maritime transportation. Recently, designing the route and schedule of ships while considering adverse weather condition has garnered significant attention as shipping companies strive to become more environmental considerate and aim to increase operational endurance [10]. Li et al. [10] classified the uncertainties in maritime transportation into two categories. The first types of uncertainties are related to port congestion, unexpected waiting time at the port and second categories of uncertainties are associated with the disruption events such as bad weather condition, labour strikes, port closure etc. Such disruption events are unpredictable in their occurrence causing unexpected closure of the port and thereby hindering vessel's operation. Few researchers addressed different recovery policies for countering disruptions within maritime transportation domain. Brouer et al. [11] discussed about vessel schedule recovery Problem (VSRP) and presented a MIP model for handling disruptions by considering recovery options like swapping two port calls or skipping a port.

\subsection{Ship Routing and Scheduling}

A vessel route comprises of several supply and demand ports, and the objective of the shipping company is to design the routes and schedules for a fleet of ships to maximize its profits and meeting the demand and supply of different ports [37]. Recent studies in the domain of vessel route and schedule design such as Agra et al. [12] have highlighted the adoption of advanced optimization approach for resolving complicated shipping logistics-related problems. Rocha $e t$ al. [13] addressed vessel routing and scheduling problem associated with the transportation of crude oil using a heterogeneous fleet of ships and Rakke et al. [14] dealt with a similar problem related to the transportation of liquefied natural gas (LNG). Majority of the earlier works overlooked the significance of addressing sustainability aspects and didn't consider the 
importance of integrating bunkering decisions with vessel routing and scheduling decisions. Most of the earlier studies focused on designing the route and schedule of vessels without addressing the sustainability aspect related to vessel fuel consumption on each sailing legs of the route. Container shipping industry has a significant role in the world economy as each year the shipping industry transports around two-thirds of the global trade which equals to USD 4 trillion and the gross GDP contribution is around USD 183.3 billion per year (http://www.worldshipping.org/benefits-of-liner-shipping/global-economic-engine). Choi et al. [15] dealt with the problem of shipment of different types of containers like 1 TEU (20-foot equivalent unit) and 2 TEUs or FEU (Forty-foot equivalent unit) using a fleet of ships. Although, the problem overlooked the increasing need of addressing bunker fuel related decisions along with the transportation of containers.

\subsection{Research Gaps}

Several researchers such as Agra et al. [12], Song et al. [16] and de Armas et al. [17] dealt with ship routing and scheduling problem yet overlooked the impacts of both sustainability aspects and fuel bunkering decisions. Few of the researchers like Fagerholt et al. [18], De et al. [4] and and De et al. [35] considered carbon emission and fuel consumption related aspects but didn't address the impact of carbon tax on their overall operational cost in the maritime transportation domain. Other scholars such as Yao et al. [19], Wang et al. [20] and Aydin et al. [5] dealt with bunker management problem but fail to distinguish it from the perspective of two types of fuel Marine Diesel Oil (MDO) and Heavy Fuel Oil (HFO) used in shipping operations. The research work carried out in this paper aims to bridge these research gaps by integrating the bunker fuel management for MDO and HFO along with ship routing and scheduling problem and addressing the sustainability aspects by including the slow steaming policy. Vessel speed helps to compute the fuel consumption, carbon emission and estimate the carbon tax incurred for the shipping company. Few articles focusing on the vessel schedule recovery under disruptions like port closure and adverse weather conditions are reported in the literature ([11] and [10]). But there is no research work being published yet which integrates the recovery strategies adopted during disruption while dealing with a ship routing and scheduling problem. It is essential to incorporate the vessel schedule recovery strategies while designing the ship route network as the majority of the practical problem faces certain kind of disruptions in the form of natural calamity, the poor weather condition in certain routes, port closure due to strike, etc. Hence, the research work 
presented in this paper addresses these issues by adopting different recovery policies to counter disruption while designing the route and schedule of the vessels with the objective to maximize the profit for the shipping company.

\subsection{Contributions}

The contributions presented in this paper aim to bridge the research gaps as mentioned earlier and addresses real-world practical problems faced in the maritime operations. The paper focusses on ship routing and scheduling problem along with loading/unloading of containers for meeting the demand at various ports. Bunker fuel management is performed for two types of fuels marine diesel oil (MDO) is used when the ship operates at the port and heavy fuel oil (HFO) is employed when the vessel sails in the sea. The paper aims to determine the bunkering decisions associated with the selection of fuel bunkering ports and estimating the amount of fuel to be bunkered. Recovery policies are adopted to deal with disruptions like port closure, weather adversities within a particular route. Slow steaming is incorporated for computing the emission and fuel consumption and determining the carbon tax. A mathematical model is developed by considering various shipping operations combined with fuel bunker management, sustainability aspects and recovery strategies for dealing with disruption. A mathematical model based heuristic combined with variable neighborhood search (VNS) algorithm is proposed for resolving the mathematical formulation. The novelty of the paper lies in formulating a robust mathematical model considering different aspects of shipping operations and devising a heuristic approach combined with VNS algorithm to solve the presented model.

The remaining part of the paper is organized in the following manner. Section 2 and Section 3 elaborately present the problem description and mathematical model respectively. Section 4 provides the recovery strategies adopted for countering disruptions. Section 5 deals with the solution methodology. Computational experiment is presented in Section 6. Conclusion and future scope are provided in Section 7. Finally, the references are given at the end of the paper.

\section{Problem Description}

Shipping companies are responsible for transporting the containers between ports to meet the customer demands. The shipping lines take decisions pertaining to routing and scheduling of vessels while aiming to reduce the transportation cost and maximize the profit of the shipping company by increasing the total revenue generated associated with the containers transportation. 
Each vessel starts its voyage from an origin port, visits several supply and demand ports, and finally finishes its journey at a destination port. The planning horizon is discretized into a set of time period equivalent to days and each ship visits several ports in different periods for performing its loading/unloading operations. The supply and demand of each container group are fixed during the planning horizon for supply and demand ports respectively. Port authorities or terminal operators allocate the quay cranes and berths to the vessels based on their arrival times with the aim to improve the service level at the port. Several ships can arrive at a port and perform their port operations depending upon the number of berths available in the time period [36]. Predominantly, the ships stay ineffective while waiting for berths and container handling facilities at the port. Some of the vessels routes may face inevitable disruptions due to adverse weather conditions, port congestions, port closure due to labour strike, etc. For recovering a vessel schedule, different recovery options are available like swapping two port calls, omitting a port from the vessel route. Weather changes quickly in different part of the world leading to closure of port for a particular period of time. In such a situation, it is necessary to make a quick decision about port skipping or swapping two-three port visits, leading to a change in the course of the vessel. Whenever the ports are located geographically close to each other, it is possible to swap the order of ports visited for countering the disruptions. Although, omitting a port call may lead to failure in meeting the demand or supply of the port, resulting in the reduction of the overall profit for the shipping company. Hence, the cancellation of certain port visit for dealing with disruption is not considered in this work as it may lead to significant monetary loss to the shipping company.

The vessel aims to perform the bunkering of two types of fuels like marine diesel oil (MDO) and heavy fuel oil (HFO) at the port for smoothly carrying out its operation throughout the planning horizon [35]. Hence, it is essential to incorporate the bunker fuel management decision associated with the selection of bunkering ports and bunkering amounts along with the routing and scheduling of the fleet of vessels. Some of the researchers dealt with bunker fuel management strategy such as Yao et al. [19], Aydin et al. [5] and interpreted that bunker fuel cost contributes to a significant portion of the total cost of the shipping company. Therefore, it is essential to decide the bunkering ports for MDO and HFO while considering the fuel price at different ports and amount of fuel to be bunkered on the ship. Vessel uses heavy fuel oil (HFO) to operate its main engine while sailing on the sea and it employs marine diesel oil (MDO) to run 
the auxiliary engine while the ship carries out its port operation [1]. It must be noted that some of the ports fall under emission control areas (ECA) which are the designated regions at sea, wherein the $\mathrm{SO}_{2}$ and $\mathrm{NOx}$ emissions need to be regulated by lowering the air pollution from ships. Hence, the ships use fuels such as marine diesel oil (MDA) which has less than $0.1 \%$ sulphur content for running its auxiliary engines during port operation associated with loading and unloading of containers. Meng et al. [21] stated about the importance of addressing the environmental aspects while designing the shipping network simultaneously, as emissions from international shipping is a subject of intense scrutiny. It is paramount to focus on lowering the $\mathrm{CO}_{2}$ emitted from the vessel while operating at the port and sailing in the sea [36]. The shipping company has to pay a certain amount of maritime carbon tax depending upon the total amount of $\mathrm{CO}_{2}$ emitted from its vessels while sailing in the sea and operating at the port. Carbon tax is an essential market-based schemes used to mitigate the carbon emission in the maritime transportation. Brouer et al. [11] stated about the potential of developing a cost saving and energy efficient shipping network using operation research is immense but neglected to some extent. Hence, a mathematical model is developed for maximizing the profit incurred for a shipping service and lowering the cost components associated with fuel bunkering, carbon tax, etc. The model aims to design the route and schedule of vessels, determine the bunker fuel management strategy including bunkering ports and bunkering amounts, vessel speed, container flowing between different ports, arrival and departure time of the ships at various ports.

\section{Mathematical Model}

The mathematical model presented in this section captures the different aspects of shipping operations such as ship routing and scheduling, loading and unloading of containers, fuel bunkering decisions, carbon emission, fuel consumption within maritime transportation domain and recovery strategies to deal with disruption. Let $c$ represents container group, $(z, p, q)$ depicts ports, $s$ represents ships, $(t, u)$ depicts the time period, $p_{s}$ represents the initial port position of ship $s, q_{d}$ depicts the destination port of ship $s$ and $f$ represents the fuel type (two types of fuel - Heavy Fuel Oil and Marine Diesel Oil). Suppose, $C$ represents the set of container groups, $P_{s}$ be the set of supply ports, $P_{d}$ depicting the set of demand ports, $P$ 
representing the set of all the ports, $P=P_{s} \cup P_{d}, S$ be the set of all the ships of the same size, $T$ depicting the set of time periods and $F$ representing the set of fuel types.

The parameters of the mathematical are represented in the following way. $B_{p t}$ depicting the number of berths available for ships at port $p$ in period $t . M_{s}$ representing the maximum number of containers that ship $s$ can load/unload and $U_{s}$ be the total number of containers that ship $s$ can carry. $\rho_{p}$ depicting the set up time for performing loading or unloading operation at port $p$ and $\eta_{p c}$ representing the loading or unloading time of container $c$ at port $p . D_{p c}$ be the demand for container group $c$ at port $p, p \in P_{d}$ and $Z_{p c}$ is the supply for container group $c$ at port $p, p \in P_{s}$. $L_{p q}$ is the distance between port $p$ and $q . w_{s}^{f}$ representing the maximum capacity of fuel type $f$ for vessel $s$ and $g_{p s t}$ is the fuel (Marine Diesel Oil) consumed by vessel $s$ at port $p$ in period $t$ (tonnes per hour). Speed range for vessel $s$ while travelling from port $p$ to $q$ in period $t$ is represented a in the following way $\left(\underline{v}_{p q s t}, \overline{v_{p q s t}}\right)$. Arrival time range depending on the high tidal scenario within which vessel $s$ can arrive at port $p$ in period $t$ is depicted as $\left(\tau_{p s t}^{S}, \tau_{p s t}^{E}\right)$ and the departure time range depending on the high tidal scenario within which vessel $s$ can depart from port $p$ in period $t$ is represented in the following way $\left(\delta_{p s t}^{S}, \delta_{p s t}^{E}\right) . \mu_{s}$ representing the number of times vessel $s$ can perform fuel bunkering. $A_{p q c}$ is the revenue generated for transporting one unit of container group $c$ from port $p$ to $q$. Fuel prices (USD per ton of fuel) of heavy fuel oil and marine diesel oil at port $p$ in period $t$ are represented as $F P_{p t}^{H F O}$ and $F P_{p t}^{M D O}$ respectively. Carbon emission coefficients (tonne of $\mathrm{CO}_{2}$ per ton of fuel) for marine diesel oil and heavy fuel oil are represented as $\mathrm{CE}_{\mathrm{CO}_{2}}^{\mathrm{MDO}}$ and $\mathrm{CE}_{\mathrm{CO}_{2}}^{\mathrm{HFO}}$ respectively. $\mathrm{CE}_{\mathrm{CO}_{2}}^{\mathrm{Tax}}$ depicts the maritime carbon tax associated with per ton of $\mathrm{CO}_{2}$ emitted. Fixed cost for performing bunkering of fuel type $f$ at port $p$ is expressed as $\pi_{p}^{f}$ and the fixed cost for carrying out loading or unloading operation at port $p$ in period $t$ is represented as $N_{p t}^{\text {oper }}$. The cost related to performing loading or unloading of one container of group $c$ at port $p$ is represented as $H_{p c}$. The parameter $R_{p t}^{C}$ takes the value 0 , if port $p$ remaining closed in time period $t$ and it takes the value 1 , if port $p$ is open in time period $t$. 
Parameter $\alpha_{p q t}^{W}$ is assigned value 0 , if the route between port $p$ to $q$ in period $t$ is affected by weather adversities, and otherwise it is assigned value 1, if the vessl can access the route between port $p$ to $q$ in period $t$. The parameter $\lambda_{p t}$ takes the value 0 , if the fuel prices at port $p$ in period $t$ is very high, otherwise it is assigned value 1, if the fuel prices at port $p$ in period $t$ is reasonable.

The decision variables of the mathematical model are expressed in the following way. The variable $y_{p q s t}$ takes the value 1 , if ship $s$ starting to sail from port $p$ to $q$ in period $t$ and 0 , otherwise. The decision variable $O_{p s t c}$ takes the value 1, if the ship $s$ performs the loading/unloading operation of container group $c$ at port $p$ in period $t$ and 0 , otherwise. The variable $x_{p s t}^{f}$ is equal to 1 , if bunkering of fuel type $f$ for vessel $s$ takes place at port $p$ in period $t$ and 0 , otherwise. The variable $q_{p s t c}$ is associated with the number of containers of group $c$ loaded onto ship $s$ at port $p$ in period $t$. The decision variable $r_{p s t c}$ is expressed as number of containers of group $c$ unloaded from ship $s$ at port $p$ in period $t$. The variable $K_{p q s t c}$ depicts the number of containers of group $c$ carried by ship $s$ while sailing port $p$ to $q$ in period $t$. The decision variable $G_{p q s t}$ represents the fuel consumption associated with Heavy Fuel Oil (tons per day) for vessel $s$ while travelling from port $p$ to $q$ in period $t$. The variable related to velocity of vessel $s$ while moving from port $p$ to $q$ in period $t$ is expressed as $v_{p q s t}$. The decision variable $E_{p s t}^{f}$ represents the fuel inventory of fuel type $f$ on vessel $s$ when it arrives at port $p$ in period $t$. The variable $A_{p s t}^{f}$ depicts the fuel inventory of fuel type $f$ on vessel $s$ while leaving port $p$ in period $t$. The decision variables $\delta_{p s t}$ and $\tau_{p s t}$ depict the departure time of vessel $s$ from port $p$ in period $t$ and arrival time of vessel $s$ from port $p$ in period $t$. 


\section{Objective function}

\section{Minimize}

$$
\begin{aligned}
& \sum_{p, q \in P} \sum_{s \in S} \sum_{t \in T} \sum_{c \in C} K_{p q s t c} A_{p q c}-\sum_{p \in P_{s}} \sum_{s \in S} \sum_{t \in T} \sum_{c \in C} H_{p c} q_{p s t c}-\sum_{p \in P_{d}} \sum_{s \in S} \sum_{t \in T} \sum_{c \in C} H_{p c} r_{p s t c}-\sum_{p \in P} \sum_{s \in S} \sum_{t \in T} \sum_{c \in C} N_{p t}^{o p e r} O_{p s t c} \\
& -\sum_{p \in P} \sum_{s \in S} \sum_{t \in T} F P_{p t}^{H F O}\left(A_{p s t}^{(f=H F O)}-E_{p s t}^{(f=H F O)}\right) x_{p s t}^{f}-\sum_{p \in P} \sum_{s \in S} \sum_{t \in T} F P_{p t}^{M D O}\left(A_{p s t}^{(f=M D O)}-E_{p s t}^{(f=M D O)}+g_{p s t}\left(\delta_{p s t}-\tau_{p s t}\right)\right) x_{p s t}^{f} \\
& -\sum_{p \in P} \sum_{s \in S} \sum_{t \in T} \sum_{f \in F} \pi_{p}^{f} x_{p s t}^{f}-C E_{C O_{2}}^{T a x}\left(C E_{C O_{2}}^{M D O} \sum_{p \in P} \sum_{s \in S} \sum_{t \in T}\left(g_{p s t}\left(\delta_{p s t}-\tau_{p s t}\right)\right)+C E_{C O_{2}}^{H F O} \sum_{p, q \in P} \sum_{t \in T} \sum_{s \in S}\left(\frac{L_{p q} G_{p q s t} y_{p q s t}}{24 v_{p q s t}}\right)\right)
\end{aligned}
$$

Equation (1) presents the objective function of the mathematical model depicting the profit associated with the shipping company. The objective function comprises of eight terms. The first term represents the revenue generated for carrying the containers between different ports. The second and third term present the cost associated with container loading and unloading respectively. The fourth term presents the fixed cost for performing the loading and unloading operation at the port. The fifth term depicts the fuel cost related to the bunkering of heavy fuel oil at the port. The sixth term is associated with the fuel cost pertaining to the bunkering of marine diesel oil at the port. The seventh term represents the fixed bunkering cost at the port. The eighth term represents the carbon tax incurred for the total $\mathrm{CO}_{2}$ emitted by consuming the marine diesel oil at the port and heavy fuel oil while sailing in the sea.

Constraint

$$
\begin{array}{ll}
\sum_{q \in P} \sum_{t \in T} y_{p_{s} q s t}=1 & \forall s \in S \\
\sum_{p \in P} \sum_{t \in T} y_{p q_{d} s t}=1 & \forall s \in S
\end{array}
$$

The equation (2) is the initial port positioning constraint ensuring that every ship must begin its journey from its origin port. Equation (3) is the route finishing constraint stating that every ship must end its route at its given destination.

$$
\sum_{p \in P} y_{p q s t}-\sum_{p \in P} y_{q p s t}=0, \quad \forall s \in S, \forall q \in P, \forall t \in T
$$


Equation (4) is the flow conservation constraint indicating that the same ship arrives at one port and leaves the same intermediate port.

$$
\begin{array}{ll}
\sum_{s \in S} y_{p q s t}=\alpha_{p q t}^{W}, & \text { For } \alpha_{p q t}^{W}=0, \forall p, q \in P, \forall t \in T \\
\sum_{q \in P} y_{p q s t} \alpha_{p q t}^{W} \geq O_{p s t c}, & \forall p \in P, \forall t \in T, \forall s \in S, \forall c \in C
\end{array}
$$

Equation (5) ensures that no ships travel through a particular route if it suffers from weather adversities. Equation (6) states that if a port performs loading and unloading operation, then it belongs to the route of a number of ships.

If $R_{p t}^{C}=0$, then $O_{p s t c}=0$, and

$$
\begin{array}{ll}
\sum_{q \in P} y_{q p s t}=R_{p t}^{C} O_{p s t c}, & \forall p \in P, \forall t \in T, \forall s \in S, \forall c \in C \\
\sum_{q \in P} \sum_{s \in S} y_{p q s t} \leq B_{p t} R_{p t}^{C}, & \forall p \in P, \forall t \in T
\end{array}
$$

Equation (7) ensures that if a port remains closed at a certain time period, then no ships will travel to that port in that particular period. The equation also ensures that if any loading/unloading operation is performed at the port in a specific period (given that the port is open in that period), then that particular port must belong to the route of the vessel. Equation (8) ensures that if the port remains open for a specific time period, then the maximum number of ships arriving at the port depends upon the number of berths available at the port in that particular time period. Such constraints are considered to avoid unnecessary congestion at the port due to the lesser number of available berths.

$$
\begin{array}{ll}
\sum_{s \in S} \sum_{c \in C} O_{p s t c} \leq B_{p t}, & \text { for } R_{p t}^{C}=1, \forall p \in P, \forall t \in T \\
q_{p s t c} \leq M_{s} O_{p s t c}, & \text { for } R_{p t}^{C}=1, \forall p \in P_{s}, \forall t \in T, \forall s \in S, \forall c \in C \\
r_{p s t c} \leq M_{s} O_{p s t c}, & \text { for } R_{p t}^{C}=1, \forall p \in P_{d}, \forall t \in T, \forall s \in S, \forall c \in C
\end{array}
$$

Equation (9) depicts that the number of ships performing its loading/unloading operation at a port depends on the availability of the berths in that period. Equation (10) and (11) ensures the maximum number of containers that a ship can load and unload at a port. 


$$
\begin{array}{ll}
\sum_{s \in S} \sum_{t \in T} r_{p s t c} \leq D_{p c}, & \forall p \in P_{d}, \forall c \in C \\
Z_{p c} \geq \sum_{s \in S} \sum_{t \in T} q_{p s t c}, & \forall p \in P_{s}, \forall c \in C \\
\sum_{c \in C} K_{p q s t c} \leq U_{s} y_{p q s t} \alpha_{p q t}^{W}, & \forall p, q \in P, \forall t \in T, \forall s \in S
\end{array}
$$

If, $y_{z p s t}=1$,

$$
K_{z p s t c}= \begin{cases}K_{p q s t c} \cdot y_{p q s t}+q_{p s t c} O_{p s t c}, & \forall p \in P_{s}, \forall z, q \in P, \forall c \in C, \forall t \in T, \forall s \in S \\ K_{p q s t c} \cdot y_{p q s t}-r_{p s t c} O_{p s t c}, & \forall p \in P_{d}, \forall z, q \in P, \forall c \in C, \forall t \in T, \forall s \in S\end{cases}
$$

Equation (12) and (13) ensures the meeting of supply and demand of the ports. Equation (14) ensures the number of containers carried by the ship should be less than the maximum storage capacity of the ship. Equation (14a) presents the relationship between containers carried by a vessel between two ports and containers loaded or unloaded at a port.

$$
\begin{array}{ll}
G_{p q s t}=\left(\beta_{1} v_{p q s t}^{3}+\beta_{2}\right) y_{p q s t}, & \forall p, q \in P, \forall t \in T, \forall s \in S \\
\underline{v_{p q s t}} \leq v_{p q s t} \leq \overline{v_{p q s t}} & \forall p, q \in P, \forall t \in T, \forall s \in S \\
v_{p q s t}=0 & \text { For } y_{p q s t}=0, \forall p, q \in P, \forall t \in T, \forall s \in S
\end{array}
$$

Equation (15) the non-linear relationship between vessel speed and fuel consumption as depicted by Yao et al. [19]. The values of the coefficient $\beta_{1}$ and $\beta_{2}$ varies for different container-ships. Container-ship of size $6000 \mathrm{TEU}$ is considered for the problem and values of $\beta_{1}$ and $\beta_{2}$ related to 6000 TEU are 0.007297 and 71.4 respectively. The range of the vessel speed is given by equation (16) and it lies between 14-24 knots as mentioned in Yao et al. [19]. Equation (17) states that in a given time period, if a vessel is not sailing from one particular port to another, then the speed of the vessel for this specific sailing leg is assumed to be zero.

$$
\begin{array}{ll}
E_{q s u}^{f}=A_{p s t}^{f}-\frac{G_{p q s} L_{p q} y_{p q s t}}{24 v_{p q s t}} & \text { For } f=\text { heavy fuel oil, } \forall p, q \in P, \forall t, u \in T, \forall s \in S \\
x_{p s t}^{f}=0 & \text { For } R_{p t}^{C}=0, \forall p \in P, \forall t \in T, \forall s \in S, \forall f \in F \\
x_{p s t}^{f}=0 & \text { For } \lambda_{p t}=0, \forall p \in P, \forall t \in T, \forall s \in S, \forall f \in F
\end{array}
$$

Equation (18) ensures that the balancing of the heavy fuel oil inventory of a ship at a port. It depicts that the amount of fuel on a vessel while arriving at a port should be equal to the fuel 
inventory of the vessel while leaving the earlier port minus the fuel consumed by the ship while sailing from the previous port to the latest port. Equation (19) states that the fuel bunkering option at a port is not available if the port is closed in a particular time period. Equation (20) ensures that no bunkering takes place at a port if the fuel prices at the port are reasonably high. The following equations (21) and (22) are considered for heavy fuel oil (here, $f$ is heavy fuel oil),

$$
\begin{array}{ll}
\left(A_{p s t}^{f}-E_{p s t}^{f}\right) R_{p t}^{C} \leq x_{p s t}^{f} w_{s}^{f} & \forall p \in P, \forall t \in T, \forall s \in S \\
\left(A_{p s t}^{f}-E_{p s t}^{f}\right) R_{p t}^{C} \geq x_{p s t}^{f} 20 \% w_{s}^{f} & \forall p \in P, \forall t \in T, \forall s \in S
\end{array}
$$

Equation (21) depicts that the amount of heavy fuel oil bunkered on the ship should be less than the maximum bunkering capacity of the vessel for the specific fuel. Equation (22) presents the minimum bunkering amount of heavy fuel oil on a vessel to be more than $20 \%$ of the total heavy fuel oil capacity of the ship. For marine diesel oil, the relationship between ship's fuel inventory, vessel arrival and departure time and fuel consumption at the port can be represented as follows (here, $f$ is marine diesel oil),

$$
\begin{array}{ll}
\left(A_{p s t}^{f}-E_{p s t}^{f}-g_{p s t}\left(\delta_{p s t}-\tau_{p s t}\right)\right) R_{p t}^{C} \leq x_{p s t}^{f} w_{s}^{f} & \forall p \in P, \forall t \in T, \forall s \in S \\
\left(A_{p s t}^{f}-E_{p s t}^{f}-g_{p s t}\left(\delta_{p s t}-\tau_{p s t}\right)\right) R_{p t}^{C} \geq x_{p s t}^{f} 20 \% w_{s}^{f} & \forall p \in P, \forall t \in T, \forall s \in S
\end{array}
$$

Equations (23) and (24) ensures that if the port is open then only a vessel can be allowed to perform the bunkering of marine diesel oil. Equation (23) presents the relationship between the bunkering amount, fuel consumed at the port and maximum fuel capacity of the vessel. Equation (24) ensures that the total amount of marine diesel oil bunkered on the vessel is always more than $20 \%$ of the maximum capacity of the ship.

$$
\begin{array}{ll}
E_{p s t}^{f} \geq 5 \% w_{s}^{f} & \text { For } x_{p s t}^{f}=1, \forall p \in P, \forall t \in T, \forall s \in S, \forall f \in F \\
A_{p s t}^{f} \leq w_{s}^{f} & \text { For } x_{p s t}^{f}=1, \forall p \in P, \forall t \in T, \forall s \in S, \forall f \in F \\
\sum_{p \in P} \sum_{t \in T} \sum_{f \in F} x_{p s t}^{f} \leq \mu_{s} & \forall s \in S
\end{array}
$$

Equation (25) depicts that the minimum fuel inventory of the vessel while arriving at the port should be more than the $5 \%$ of the total bunkering capacity of the ship. Equation (26) presents 
the capacity constraint for the vessel. This constraint states that while leaving the port the bunker fuel inventory of the ship should be less than the fuel tank capacity of the vessel. Number of the times the ship carries out the bunkering of fuel is given by the equation (27).

$$
\begin{array}{ll}
\alpha_{p q t}^{W}\left(\delta_{p s t}+\frac{L_{p q}}{v_{p q s t}}-\tau_{q s u}\right) y_{p q s t} \leq 0, & \forall p, q \in P, \forall t, u \in T, \forall s \in S \\
\left(\tau_{p s t}+\rho_{p} \sum_{c \in C} O_{p s t c}+\sum_{c \in C} \eta_{p c} r_{p s t c}-\delta_{p s t}\right) R_{p t}^{C} \leq 0 & \forall p \in P_{d}, \forall t \in T, \forall s \in S \\
\left(\tau_{p s t}+\rho_{p} \sum_{c \in C} O_{p s t c}+\sum_{c \in C} \eta_{p c} q_{p s t c}-\delta_{p s t}\right) R_{p t}^{C} \leq 0 & \forall p \in P_{s}, \forall t \in T, \forall s \in S \\
\tau_{p s t}^{S} \leq \tau_{p s t} \leq \tau_{p s t}^{E} & \forall p \in P, \forall t \in T, \forall s \in S \\
\delta_{p s t}^{S} \leq \delta_{p s t} \leq \delta_{p s t}^{E} & \forall p \in P, \forall t \in T, \forall s \in S
\end{array}
$$

Equation (28) presents the relationship between vessel speed, arrival and departure time of the vessel. The equation also takes into account the possibility of weather adversities while sailing from one port to another. Equation (29) relates the arrival and departure time of a vessel with the setup time and total unloading time at a demand port. Equation (30) depicts the arrival and departure time of the ship at a supply port considering the total loading time of different groups of containers on the ship. Moreover, the gross weight of 20-foot group of containers and 40-foot group of containers are assumed to be constant. Arrival time range and departure time range depends on the high tide scenario of the port and given by equations (31) and (32) respectively.

$$
\begin{array}{ll}
y_{p q s t} \in\{0,1\} & \forall p, q \in P, \forall t \in T, \forall s \in S \\
O_{p s t c} \in\{0,1\} & \forall p \in P, \forall t \in T, \forall s \in S, \forall c \in C \\
x_{p s t}^{f} \in\{0,1\} & \forall p \in P, \forall t \in T, \forall s \in S, \forall f \in F \\
q_{p s t c} \geq 0 & \forall p \in P_{s}, \forall t \in T, \forall s \in S, \forall c \in C \\
r_{p s t c} \geq 0 & \forall p \in P_{d}, \forall t \in T, \forall s \in S, \forall c \in C \\
K_{p q s t c} \geq 0 & \forall p, q \in P, \forall t \in T, \forall s \in S, \forall c \in C \\
G_{p q s t}, v_{p q s t} \geq 0 & \forall p, q \in P, \forall t \in T, \forall s \in S \\
E_{p s t}^{f}, A_{p s t}^{f} \geq 0 & \forall p \in P, \forall t \in T, \forall s \in S, \forall f \in F
\end{array}
$$


$\tau_{p s t}, \delta_{p s t} \geq 0$

$$
\forall p \in P, \forall t \in T, \forall s \in S
$$

Equations (33) - (35) are the binary variables and equations (36) - (38) present the integer variables. Equations (39) - (41) depict the continuous variables.

\section{Recovery Strategies Adopted for Countering Disruptions}

The sustainable ship routing and scheduling with bunker fuel management problem is considered for a planning horizon of sets of time periods equivalent to days. Here, the model considers two different kinds of disruption - adverse weather condition affecting the sailing leg between two ports and port closure on a certain period due to bad weather or labour strike etc. The vessel opts to reschedule its route for avoiding any kinds of disruptions. As the disruption can be limited to a period (or day), hence it is essential to avoid that disrupted sailing leg or the port facing disruption on that period (or day) and reschedule the vessel route accordingly. As the duration of disruption is usually shorter or limited to a length of the period (or day), hence it is appropriate to opt for different recovery strategies such as swapping two port visit for dealing with port closure on a specific period and rescheduling the vessel route for avoiding a disrupted sailing leg. Figure (1) depicts an example of the disruption on the sailing route between two ports. In the first case, the ship's route comprises of the ports p1, p2, p3, p4, p5, p6 and p7. Although, the sailing leg between p4 and p5 is disrupted and needs to be omitted from the sailing route, yet the vessel should visit all the ports. In the second case, the voyage of the vessel remains same from p1 to p4. From p4, the ship sails to p6 and then travels to p5 and finally ends at p7. In the second scenario, the vessel route comprises of the ports p1, p2, p3, p4, p5 and p6 in the following order as it should be visited. The order of the port visit is changed due to the disruption between the port pair p4 and p5. Hence, the order of the newly formed route of the ship is p1, p2, p3, p4, p6 and $\mathrm{p} 5$.

Now, some of the ports remain closed for a given time period due to various issues like poor weather condition, labour strike, etc. Figure 2 illustrates an example of the recovery of a vessel's route and schedule. Initially, the vessel sails from port $1(\mathrm{p} 1)$ to port $2(\mathrm{p} 2)$ and operates at p2 in period 3 and then moves to port 3 (p3) in period 3 and finally ends its voyage at port 4 (p4) in period 4. As the port $2(\mathrm{p} 2)$ is closed on period 2 hence, the route of the vessel needs to be changed appropriately. The newly formed route allows the vessel to move from port 1 (p1) to port $3(\mathrm{p} 3)$ and perform its operation at $\mathrm{p} 3$ in period 2 . Then it sails from port 3 (p3) to port 2 
(p2) and carries out its operation at p2 in period 3 and later, it sails to port 4 (p4) for performing its operation and finally ends its voyage at P4. Figures (1) and (2) give an idea of the recovery procedure of the route and schedule of the vessel for different circumstances.

$$
\begin{aligned}
& <\text { Insert Figure 1 >> } \\
& <<\text { Insert Figure 2>> }
\end{aligned}
$$

\section{Solution Methodology}

The mathematical model needs to be validated with respect to different problem sizes as mentioned in Table (1). The main difficulty in solving such a complicated mathematical model is the presence of large number of variables, inequality and equality constraints. It can be noted that for each of the problem instances, the number of variables and constraints are significantly increasing. It is stated that operation research based solvers such as CPLEX, LINGO, etc. and exact methods need huge memory requirements and high computational time for dealing with even a small-size problem instances [22]. Several researchers stressed on the fact that lack of robust exact heuristic methods for dealing with mixed integer non-linear programming model makes it imperative to opt for random search heuristics or intelligent search-based techniques for solving such problems ([23], [24], [25] and [26]). The application of heuristics methods for resolving constrained non-linear optimization problems in the domain of shipping operations are well reported ([17], [27], [35] and [37]).

\section{$<<$ Insert Table 1 >>}

A mathematical model based heuristic approach combined with variable neighbourhood search algorithm is presented in this section to resolve the mathematical model illustrated earlier. At first, the routing variable $y_{p q s t}$ is generated for all the ships considering the overall planning horizon. The routing variable $y_{p q s t}$ is updated depending upon the types of disruptions faced by the vessel. The values generated for routing variable $y_{p q s t}$ satisfies the equations (2) and (3) as each of the vessel starts from a particular origin port and ends its voyage at a specified destination port. Equation (4) of the mathematical model depicting the flow conservation constraint is also satisfied while determining the routing variable $y_{p q s t}$. Weather adversities on any route are taken into account, and simultaneously the variable $y_{p q s t}$ is updated accordingly, 
thereby satisfying constraint (5). If any port is closed for a particular time period, then all the ships avoid travelling to that port in the specific period. Figure (2) shows the rescheduling of the vessel route due to the closure of a port. The routing variable $y_{p q s t}$ is updated while satisfying equation (8). Now, the binary variable associated with the loading or unloading operation at a port $O_{p s t c}$ is generated using the routing variable $y_{p q s t}$ and equations (6) and (7). Numbers of berths available at a port are taken into account while generating the values of the variable $O_{p s t c}$ and hence satisfying equation (9).

\subsection{Initialization of Loading/Unloading Variables and Container Flow}

A heuristic method is proposed to determine the number of containers loaded and unloaded at a supply and demand port respectively. The number of containers flowing from one port to another is also estimated using the values pertaining to the container loaded or unloaded at a port. The number of containers loaded on the vessel at a supply port can be determined considering the supply of the container groups at the port and number of ships employed by the shipping company. Container unloaded from the ship at the demand port can be computed considering the demand of the container group to be met at the port.

A new variable $Q_{p s t c}$ is defined in the pseudo code which stores the values of both $q_{p s t c}$ and $r_{p s t c}$ . The heuristic procedure aims to satisfy the supply and demand constraints given in equations (12) and (13) respectively. Equations (10) and (11) depict the condition of the number of containers loaded or unloaded at a port should be less than the maximum number of containers loaded or unloaded by a ship. Both this conditions are satisfied while generating the values of the loading/ unloading variables $q_{p s t c}$ and $r_{p s t c}$. The relationship between variables $K_{p q s t c}$ and $Q_{p s t c}$ is used to compute the value of the container flow variable $K_{p q s t c}$. The parameter $A_{p q c}$ provides the value associated with the revenue generated for carrying one unit of a specific container group from one port to another. Hence, using the value of $K_{p q s t c}$ and $A_{p q c}$, the revenue generated for the shipping company can be obtained. The value generated for container flow variable $K_{p q s t c}$ satisfies the equation (14) as the value obtained for $K_{p q s t c}$ is always less than the maximum capacity of the ship. Using equation (14b) and new variable $Q_{p s t c}$, the relationship between variables $K_{p q s t c}$ and $Q_{p s t c}$ can be depicted in the following way, 
If, $y_{z p s t}=1, K_{z p s t c}= \begin{cases}K_{p q s t c} \cdot y_{p q s t}+Q_{p s t c} O_{p s t c}, & \forall p \in P_{s}, \forall z, q \in P, \forall c \in C, \forall t \in T, \forall s \in S \\ K_{p q s t c} \cdot y_{p q s t}-Q_{p s t c} O_{p s t c}, & \forall p \in P_{d}, \forall z, q \in P, \forall c \in C, \forall t \in T, \forall s \in S\end{cases}$

\subsection{Initialization of Vessel Speed and Fuel Consumption at Port and Sea}

Yao et al. [19] presented a speed range for a 6000 TEU capacity of ship and accordingly provided the relationship between vessel speed and fuel consumption which is depicted in equation (15). The range of the vessel speed variable is given by equation (16). Upper limit and lower limit of the vessel speed variables is given as $\underline{v_{p q s t}}=14$ knots and $\overline{v_{p q s t}}=24$ knots. The speed range 14-24 knots is given by Yao et al. [19] for a vessel with a capacity of 6000 TEU. The value of the vessel speed variable $v_{p q s t}$ is randomly generated within the given range of $\left(\underline{v_{p q s}}, \overline{v_{p q s t}}\right)$ or 14 to 24 knots considering the value of the routing variable $y_{p q s t}$. The heavy fuel oil consumption for each vessel can be estimated (in terms of tonnes per day) using the vessel speed value and equation (15), $G_{p q s t}=\left(\beta_{1} v_{p q s t}^{3}+\beta_{2}\right) y_{p q s t}$. The total heavy fuel oil consumed while sailing from one port to another $\left(y_{p q s t}=1\right)$ can be computed by considering the distance between two ports (in terms of nautical mile) and it is represented as Fuel_ $H F O=\frac{G_{p q s t} \times L_{p q}}{24 v_{p q s t}}$.

Total fuel (marine diesel oil) consumed at the port is related to the number of hours spent by the ship at the port and it can be determined from equations (29) and (30). Suppose a demand/supply port is open in a specific period ( $R_{p t}^{C}=1, p \in P$ ) and the vessel performs its operation at the port, then the total service time for the vessel can be deduced from equation (29).

From equation (29), $\tau_{p s t}+\rho_{p} \sum_{c \in C} O_{p s t c}+\sum_{c \in C} \eta_{p c} r_{p s t c}-\delta_{p s t} \leq 0$, for $R_{p t}^{C}=1, p \in P$ or, $\rho_{p} \sum_{c \in C} O_{p s t c}+\sum_{c \in C} \eta_{p c} r_{p s t c} \leq \delta_{p s t}-\tau_{p s t}$,

or, $\delta_{p s t}-\tau_{p s t} \geq \rho_{p} \sum_{c \in C} O_{p s t c}+\sum_{c \in C} \eta_{p c} r_{p s t c}, \quad \forall p \in P_{d}, \forall t \in T, \forall s \in S$

Equation (42) presents the service time of the vessel operating at a demand port. Similarly, the service time at a supply port can be presented in the following way using equation (30), 


$$
\delta_{p s t}-\tau_{p s t} \geq \rho_{p} \sum_{c \in C} O_{p s t c}+\sum_{c \in C} \eta_{p c} q_{p s t c}, \quad \forall p \in P_{s}, \forall t \in T, \forall s \in S
$$

So, the total amount of time spent by the ship at the port depends upon the number of containers loaded or unloaded depending upon the type of port.

Definition 1: A non-negative integer variable $Q_{p s t c}$ is defined considering the variables $q_{p s t c}$ and $r_{p s t c}$.

$$
Q_{p s t c} \geq 0, \quad \forall p \in P, \forall t \in T, \forall s \in S, \forall c \in C
$$

So, equations (42) and (43) can be expressed in a single equation,

$$
\delta_{p s t}-\tau_{p s t} \geq \rho_{p} \sum_{c \in C} O_{p s t c}+\sum_{c \in C} \eta_{p c} Q_{p s t c} \quad \forall p \in P, \forall t \in T, \forall s \in S
$$

Total number of container loaded/unloaded at a port by a particular ship can be computed using the value of the variable $Q_{p s t c}$,

$$
\text { Total_container }=\sum_{c \in C} Q_{p s t c} \quad \forall p \in P, \forall t \in T, \forall s \in S
$$

Proposition 1: The amount of marine diesel oil (MDO) consumed by the ship while performing its port operation is related to the total numbers of containers loaded or unloaded at a port.

Proof: From equation (43), total time spent by the vessel at a port can be estimated in the following way, Time spent by a ship $=\delta_{p s t}-\tau_{p s t} \geq \rho_{p} \sum_{c \in C} O_{p s t c}+\sum_{c \in C} \eta_{p c} Q_{p s t c}$. So, fuel consumed by a ship at a port can be represented as,

Fuel_MDO $=\left(g_{\text {pst }} \times\right.$ Time spent by a ship $)$

or, Fuel_MDO=(g $\left.g_{p s t} \times\left(\delta_{p s t}-\tau_{p s t}\right)\right) \geq\left[g_{p s t} \times\left(\rho_{p} \sum_{c \in C} O_{p s t c}+\sum_{c \in C} \eta_{p c} Q_{p s t c}\right)\right]$

Fuel_MDO=[g $\left.g_{p s t} \times\left(\rho_{p} \sum_{c \in C} O_{p s t c}+\sum_{c \in C} \eta_{p c} Q_{p s t c}\right)\right] \quad \forall p \in P, \forall t \in T, \forall s \in S$

Thus, the marine diesel oil (MDO) consumed by the vessel while carrying out the loading/unloading operation at the port is computed using the equation (47). Fuel (MDO) consumed by the vessel is directly proportional to the numbers of containers loaded or unloaded. Therefore this completes the proof. 


\subsection{Initialization of Bunker Fuel Consumption and Bunkering Ports}

In reality, the vessel always starts its voyage from an initial port position with a maximum bunker fuel capacity and then sails to other ports according to its port of calls. Considering this scenario, the assumption (1) is presented.

Assumption 1: It is assumed that the vessel starts its operation from the initial port with a fuel capacity up to the maximum capacity of the ship.

Based on the assumption 1, the values of the variables $E_{p s t}^{f}$ and $A_{p s t}^{f}$ at the initial port position of a vessel for both types of types of fuel can be depicted as,

$E_{p s t}^{f}=w_{s}^{f}$, Where $\forall f \in F$

$A_{p s t}^{f}=E_{p s t}^{f}$, for $f=$ Heavy fuel oil

$A_{p s t}^{f}=E_{p s t}^{f}-$ Fuel_MDO, for $f=$ Marine Diesel oil

Figure (3) presents the pseudo-code of the algorithm for estimating the values related to the heavy fuel oil (HFO) inventory and marine diesel oil (MDO) while arriving and departing from the port. The algorithm depicted in figure (3) also determines the ports where the bunkering of heavy fuel oil and marine diesel oil are performed. The pseudo-code presented in figure (3) is referred to as the bunkering activities related to heavy fuel oil and marine diesel oil.

Assumption 2: The bunkering of the heavy fuel oil or marine diesel oil can be performed when the ship's fuel inventory after arriving at the port is less than the threshold limit. (Here, threshold limit is 50\% of the maximum fuel capacity of the vessel and it is considered arbitrarily) [28].

Zhen et al. [28] stated about the threshold based policy for performing the fuel bunkering at a port and accordingly assumption (2) is justified. Also, only when the fuel price is reasonable, the bunkering of the respective fuel can be carried out. Hence, both the conditions need to be satisfied for performing the bunkering at a port.

Proposition 2: If the port is open and bunkering of heavy fuel oil is performed at the port, then, for $R_{p t}^{C}=1, x_{p s t}^{f}=1$ and $f=$ Heavy fuel oil, equation (21) is always satisfied. 
Proof: If the maximum capacity of the vessel for heavy fuel oil and the value of the variable $E_{p s t}^{f}$ is known, then the bunkered amount for heavy fuel oil at a port can be depicted in the following way,

Bunkered_amount $=$ Maximum_HFO $-E_{p s t}^{f}$, where $f=$ Heavy fuel oil

As, Maximum_HFO $=w_{s}^{f}$, where $f=$ Heavy fuel oil

Hence, Bunkered_amount $=w_{s}^{f}-E_{p s t}^{f}$, for $f=$ Heavy fuel oil

$A_{p s t}^{f}=$ Bunkered_amount $+E_{p s t}^{f}$, for $f=$ Heavy fuel oil

So, the fuel inventory (HFO) of the vessel while leaving the port can be estimated from equation (50) by considering the bunkered amount and the fuel inventory (HFO) of the vessel while arriving at the port.

Considering equations (49) and (50),

$A_{p s t}^{f}-E_{p s t}^{f}=$ Bunkered_amount $=w_{s}^{f}-E_{p s t}^{f}$, or, $A_{p s t}^{f}-E_{p s t}^{f}=w_{s}^{f}-E_{p s t}^{f} \leq w_{s}^{f}$

Hence, this completes the proof.

Now, while the ship consumes certain heavy fuel oil during its sailing to the next port and it can be computed by the following equation,

Fuel_HFO $=\frac{G_{p q s t} \times L_{p q}}{24 v_{p q s t}} \quad \forall p, q \in P, \forall t \in T, \forall s \in S$

Heavy fuel oil inventory of the vessel once it arrives at the next port is estimated using the equation (18).

$E_{q s u}^{f}=A_{p s t}^{f}-\frac{G_{p q s t} \times L_{p q}}{24 v_{p q s t}} \quad$ For, $f=$ Heavy fuel oil and $y_{p q s t}=1$

or, $E_{q s u}^{f}=A_{p s t}^{f}-$ Fuel_HFO $\quad$ For, $f=$ Heavy fuel oil

Assumption 3: Considering $E_{p s t}^{f} \geq 5 \% w_{s}^{f}$ or equation (25), the bunkering fuel inventory (heavy fuel oil) of a vessel while arriving at a port having a certain minimum level of $5 \%$ of the maximum fuel inventory [19]. 
Yao et al. [19] considered a constraint ensuring that the bunker fuel inventory while arriving at the port has a certain minimum level of $5 \%$ of bunker fuel capacity of a ship.

Proposition 3: Considering assumptions (2) and (3), the equation (22) of the mathematical model is always satisfied.

Proof: If the port is open and bunkering of heavy fuel oil is performed, then equation (22) can be represented as, $A_{p s t}^{f}-E_{p s t}^{f} \geq 20 \% w_{s}^{f}$, For $R_{p t}^{C}=1, x_{p s t}^{f}=1 f=$ Heavy fuel oil

Once the bunkering of heavy fuel oil is performed, then after bunkering, using equation (49) and (50), the following relationship can be obtained,

$A_{p s t}^{f}=$ Bunkered_amount $+E_{p s t}^{f}=w_{s}^{f}-E_{p s t}^{f}+E_{p s t}^{f} \Rightarrow A_{p s t}^{f}=w_{s}^{f}$

So, as the fuel bunkering takes place, the equation (53) can be represented as, $A_{p s t}^{f}-E_{p s t}^{f} \Rightarrow w_{s}^{f}-30 \% w_{s}^{f}>20 \% w_{s}^{f}$

Considering, $E_{p s t}^{f}=30 \% w_{s}^{f}$ where, $E_{p s t}^{f}=30 \% w_{s}^{f}<50 \% w_{s}^{f}$ using assumption 2 (bunkering takes place if $E_{p s t}^{f}$ is less than a threshold limit and over here the threshold limit is considered as $50 \% w_{s}^{f}$ ) and $E_{p s t}^{f}=30 \% w_{s}^{f}>5 \% w_{s}^{f}$ using assumption 3 (bunker fuel inventory while arriving at the port should always be greater than $5 \% w_{s}^{f}$ ).

Hence, equation (22) $A_{p s t}^{f}-E_{p s t}^{f} \geq 20 \% w_{s}^{f}$ of the mathematical model is satisfied, and this completes the proof.

Assumption 4: Bunkering of marine diesel oil (MDO) takes place at a port only if the fuel (MDO) inventory of the vessel while arriving at the port is less than the fuel (MDO) consumed by the ship at the port or $\left(E_{p s t}^{f}<F u e l_{-} M D O\right)$.

The assumption (4) is quite logical as the bunkering of marine diesel oil (MDO) should be performed only when the total fuel (MDO) required at the port for running the auxiliary engines is more than the available fuel inventory (MDO) on the vessel when it arrives at the port. 
Assumption 5: If the bunkering of marine diesel oil (MDO) is performed at a port, then the fuel inventory of the vessel while leaving the port $A_{p s t}^{f}$ should be equal to the maximum MDO capacity of the vessel.

The bunker fuel price can be very high at certain port in specific time period leading to no bunkering at that particular port. For avoiding such scenarios, it is essential for the vessel to have adequate amount of marine diesel oil while arriving at such ports. Thus, while performing the bunkering of marine diesel oil at other ports, the vessel should bunker up to the maximum fuel capacity of the vessel. Considering the above condition, assumption (5) is presented which will help the vessel to counter the scenario of very high fuel price at certain ports.

Proposition 4: If a port is open and bunkering of marine diesel oil takes place, then the equation (23) of the mathematical model is always satisfied.

Proof: Fuel (MDO) inventory of the vessel at a port while leaving the port can be represented in the following way,

$A_{p s t}^{f}=$ Bunkered_amount $+E_{p s t}^{f}-g_{p s t}\left(\delta_{p s t}-\tau_{p s t}\right)$

or, $A_{p s t}^{f}-E_{p s t}^{f}+g_{p s t}\left(\delta_{p s t}-\tau_{p s t}\right)=$ Bunkered_amount

or, Bunkered_amount $=A_{p s t}^{f}-E_{p s t}^{f}+g_{p s t}\left(\delta_{p s t}-\tau_{p s t}\right)$

Using equation (45) and (47), Fuel_MDO $=\left(g_{p s t} \times\left(\delta_{p s t}-\tau_{p s t}\right)\right)$

Hence, equation (55) can be presented in the following way,

Bunkered_amount $=A_{p s t}^{f}-E_{p s t}^{f}+F_{u e l}$ MDO

Considering assumption 5, if bunkering of MDO is performed, then the fuel inventory of the vessel while leaving the port can be the represented in the following way,

$A_{p s t}^{f}=$ Maximum_MDO $=w_{s}^{f}, \quad$ where $f=$ Marine Diesel oil

So, Bunkered_amount $=w_{s}^{f}-E_{p s t}^{f}+F_{u e l}$ MDO

As the port is open, equation (23) can be written in the following way, $\left(A_{p s t}^{f}-E_{p s t}^{f}-g_{p s t}\left(\delta_{p s t}-\tau_{p s t}\right)\right) \leq w_{s}^{f} \quad$ For $R_{p t}^{C}=1, x_{p s t}^{f}=1 f=$ Marine Diesel oil 
Substituting the value of $A_{p s t}^{f}$ given in equation (59) and considering that bunkering of marine diesel oil takes place,

$\left(w_{s}^{f}-E_{p s t}^{f}-g_{p s t}\left(\delta_{p s t}-\tau_{p s t}\right)\right)$ which is always less than $w_{s}^{f}$ and equation (23) is satisfied.

Hence, this completes the proof. Boundary conditions for the variables $E_{p s t}^{f}$ and $A_{p s t}^{f}$ presented in equations (25) and (26) respectively are satisfied while generating their values.

$<<$ Insert Figure 3>>

\subsection{Initialization of Arrival and Departure Time of the Vessel}

The starting time of the port operation for the vessel at its initial port position is known beforehand.

Proposition 5: If the starting time of an operation for a vessel at its initial port position is known, then the arrival and departure time of the vessel for all the port of calls can be estimated.

Proof: The service time at the port is computed using the equation (45),

$$
\text { Service_time }=\delta_{p s t}-\tau_{p s t} \geq \rho_{p} \sum_{c \in C} O_{p s t c}+\sum_{c \in C} \eta_{p c} Q_{p s t c}, \text { Service_time }=\rho_{p} \sum_{c \in C} O_{p s t c}+\sum_{c \in C} \eta_{p c} Q_{p s t c}
$$

The arrival time of the vessel at its initial port is known and the service time can be computed from equation (60). The departure time of the vessel from its initial port can be estimated using the following equation,

$$
\delta_{p s t}=\text { Service_time }+\tau_{p s t}
$$

Once the ship departs from the port, then it sails from one port to another. The travelling time between the two ports needs to be computed to determine the arrival time of the vessel at the next port. The travelling time is given by the following equation,

Travel_time $=\left\lceil\frac{L_{p q}}{v_{p q s t}}\right\rceil$

The value of the travelling time (in hour) between two ports is estimated to be as integer value. Hence, the ceiling function is considering in equation (62) to obtain the least integer value greater than or equal to $\left(L_{p q} / v_{p q s t}\right)$. The arrival time for the next port can be found using the 
departure time from the last port and the travelling time between the two ports. Given that $\alpha_{p q t}^{W}=1$ and $y_{p q s t}=1$, equation (28) can be represented in the following way,

$$
\left(\delta_{p s t}+\frac{L_{p q}}{v_{p q s t}}-\tau_{q s u}\right) \leq 0, \text { or, } \tau_{q s u} \geq \delta_{p s t}+\frac{L_{p q}}{v_{p q s t}} \quad \forall p, q \in P, \forall t, u \in T, \forall s \in S
$$

The arrival time of the vessel at the next port can be estimated from equation (63). As the service time of the vessel at each port is known, hence the departure time can be computed using equation (61). Similarly, the arrival and departure time of the vessel for each port of call can be determined. Hence, this completes the proof. Figure (4) presents the pseudo-code for computing the arrival and departure time of the vessel at different ports.

$$
<<\text { Insert Figure 4>> }
$$

\subsection{Variable Neighborhood Search Algorithm}

The heuristic approach described in the earlier part of section 5 is used to obtain the neighborhood structure of the variable neighborhood search (VNS) algorithm. Several researchers such as Jarboui et al. [29], Belhaiza et al. [30] and Mladenović et al. [31] have employed this algorithm for different types of problems like location routing, vehicle routing, travelling salesman problem and security in a utility network respectively and obtained highquality results. De Armas et al. [17] presented a hybrid algorithm of variable neighborhood search with a greedy randomized adaptive search procedure for resolving a ship routing and scheduling domain and obtained good results in less computational time. VNS algorithm is straightforward and easy to implement than other meta-heuristics as it contains a list of neighborhoods searched sequentially [17]. VNS algorithm also proved to be powerful and elegant in dealing with a variety of combinatorial optimization problems [32]. The operational problem related to shipping operations presented in this paper is complicated and need to be solved quickly and provide results of highest possible quality. Motivated by this, the hybrid approach comprising of the model-based heuristic combined with variable neighborhood search is proposed in the paper for solving the problem presented in the aforementioned section and obtaining desired results.

Variable neighborhood search (VNS) algorithm carries out the searching procedure within several neighborhood structures to escape from any local entrapment and find the near-optimal solution. The neighborhood structure consists of each type of variables related to ship routing, 
loading/unloading operation, container flow, bunkering decisions, vessel speed, fuel consumption, arrival and departure time of the ship. The neighborhood generation is the fundamental part of the algorithm which comprises of different variables, and it is elaborated in the earlier sections. Figure 5 depicts the pseudo code for the variable neighborhood search algorithm. A maximum number of neighborhood structures and the number of iterations are the VNS parameters. VNS algorithm has different operators like shaking procedure, first improvement and neighborhood change. Let $p$ be a feasible solution and $M_{k}(p)$ be the set of all the solutions in the $k^{\text {th }}$ neighborhood of the solution $p . K_{\max }$ is referred to the maximum number of neighborhood structures generated in the shaking procedure step. The algorithm starts with the shaking procedure where a solution is randomly chosen from the all the neighborhood structures. Once the shaking step ends, the algorithm moves into the first improvement stage and performs the local search within the given neighborhood structure and compares each solution of the neighborhood with the solution obtained in the shaking procedure. The best solution obtained in the first improvement stage is compared with the overall best solution in the neighborhood change procedure. If a better solution is achieved, then the local search is again performed on the current neighborhood structure and updates the overall best solution. The algorithm moves on to a different neighborhood structure if no further improvement in solution is possible. In this way, the algorithm carries out the local search in all the neighborhood structure and stores the best solution and then moves on to the next iteration. Once the maximum numbers of iterations are reached, the VNS algorithm terminates and provides the best possible solution after performing a thorough local search. Figure 6 presents a neighborhood structure comprising of several solutions.

$$
\begin{aligned}
& <<\text { Insert Figure 5>> } \\
& <<\text { Insert Figure 6>> }
\end{aligned}
$$

\section{Computational Experiment}

This section presents the comparative analysis of the results obtained by the proposed heuristic combined with the variable neighborhood search algorithm. Different problem instances as mentioned in Table 1 are generated considering the examples of real-world problems of the international shipping companies. As illustrated in Table 1, medium and large sized problem instances are obtained by varying the number of supply and demand ports, time periods and 
vessels. Two types of fuel oils (heavy fuel oil (HFO) and marine diesel oil (MDO)) are considered for all the problem instances as mentioned in the earlier sections.

\subsection{Experimental Setting, Computational Complexity and Data Collection}

All the computational experiments performed on different problem instances are conducted on MATLAB R2015b software having 8GB RAM with Intel Core i7 $1.8 \mathrm{GHz}$ processor and 64-bit Windows 7 operating system. The number of solutions examined by the algorithm can be computed as, solution $\times$ number of neighborhoods $\times$ number of iteration $=100 \times 50 \times 100=$ 500,000 . The algorithm performs an intensive search to find the best possible solution for each of the problem instances presented in Table 1. The computational complexity of the experiments can be observed from the number of solutions handled and dealing with a large number of variables and constraints. The problem instances categorized into medium and large scale with increasing complexity are considered to validate the proposed mathematical formulation extensively. The estimation of some of the parameters is made from the real data, as they are not available or difficult to collect. The relevant parameter values used for this illustrative example are presented in Table 2. The data required for carrying out the computational experiments are generated from several reliable sources such as Barnhart et al. [33], HSU et al. [34] and De et al. [2]. Values related to the container shipping rates are taken from internet sources (https://moverdb.com/container-shipping/\#size). Bunker prices for all the ports concerning different types of fuel are borrowed from some secondary sources (https://shipandbunker.com/prices). Distances between ports are considered after studying different route networks and their schedule for the Maersk Line (http://www.maerskline.com/shipping-services/routenet/maersk-line-network/overview). The problem instances for the computational experiment are inspired by the real-world problem associated with shipping services of Maersk Line. Various container groups belonging to different shipping companies are transferred to meet the demands.

Some of the parameter values of the mathematical model such as number of berths available at the port, time window range of a port, capacity of the port, penalty charges and other fixed and variable costs of the port etc. are known to the port managers. This information is transferred to the shipping company as they perform the optimization for finding the suitable route and schedule for their ships. Certain information obtained after running the mathematical model 
related to the possible ship routes, vessel speed, arrival time of different ships at the port, loading/unloading quantity at a port from the vessel etc. are passed on to the terminal managers from the shipping companies. Hence, it can be concluded that a high level of information sharing takes place between port manager and shipping companies.

\subsection{Illustrative Example}

The case is designed after studying the various service routes of Maersk Line shipping company such as Intra Asia 4 (IA4) Northbound, Intra Asia 2 (IA2) Northbound etc. (http://www.maerskline.com/en-us/shipping-services/routenet/maersk-line-network/intra-asia).

For determining the route network of the ship, fuel bunkering amounts and bunkering ports; all the relevant parameters of the mathematical model need to be appropriately generated. Some of the output deliverables after solving the mathematical model are vessel speed and fuel consumption for different ships, vessel's routing decisions considering disruption, maximized profit of the shipping company, container flow on various legs, bunkering ports, fuel bunkered, arrival and departure time of the vessel. The illustrative example deals with six supply ports, six demand ports (overall twelve ports), fourteen time periods, two ships, two container groups and two types of fuel oils (HFO and MDO). This illustrative example is based on the problem instance 1 presented in Table 1. Table 3 presents the values related to the profit, revenue generated for all the problem instances and different cost components such as loading and unloading cost, bunkering cost for MDO and HFO, carbon tax, etc.

The problem addressed in the paper aims to design vessel route and schedule for an overall planning horizon comprising of time periods (discretized into days). The illustrative example is the first problem instance present in table 1 . The number of periods considered for the first problem instance (supply ports $=6$, demand ports $=6$, time periods $=14$, types of container groups $=2$, ships $=2$, types of fuel $=2$ ) is 14 periods equivalent to 14 days. Six demand ports and six supply ports are taken into account for this problem instance. For the first problem instance, $Z_{p c}$ is the supply of container group $c$ (two types of container groups) at supply ports (6 supply ports) considering an overall planning of 14 times periods (equivalent to 14 days) and $D_{p c}$ is the demand for container group $c$ (two types of container groups) at the demand ports (6 demand ports) for a planning horizon of 14 periods (equivalent to 14 days). The supply and demand for each port pertaining to each container group are considered to be fixed for an overall 
planning horizon of 14 periods (equivalent to 14 days) for the problem instance. Initially, the vessels visit the supply ports and perform its loading operation and then sails to each demand ports according to its port of calls and performs its unloading operation and this overall voyage is carried out within a planning horizon of 14 time periods equivalent to 14 days.

\subsubsection{Results of the illustrative example}

The illustrative example refers to problem instance 1 presented in Table 3 . The total amount of revenue generated and profit incurred for the illustrative example are USD 34,051,896 and USD 26,523,252.83 respectively. Different cost components of the illustrative example are mentioned in the table. The order of port visits for both the ships are mentioned in Tables 4 and 5 along with their arrival and departure time at each port. Total numbers of each container groups loaded/unloaded from the ships are also represented in Tables 4 and 5. Table 4 presents the results of the first ship of the illustrative example and the port of calls for the first ship are P5, P1, P2, P6, P4, P3, P12, P9, P11, P8, P7 and P10. Initially, the ship visits the supply ports and performs its port operations by loading both types of container groups on the vessel and later, the vessel visits the demand ports to carry out the unloading of the containers. The arrival, departure and service time of the ship at each port is mentioned in the table. Bunker fuel inventory on the ship for each type of fuel (HFO and MDO) while arriving and leaving the port are presented in the table. The first ship performs the bunkering of heavy fuel oil at port 4 (P4) and port 11 (P11), and the bunkered amount is 631.11 tons at $\mathrm{P} 4$ and 627.98 tons at $\mathrm{P} 11$. The vessel performs bunkering of marine diesel oil at four ports - port $1(\mathrm{P} 1)$, port $4(\mathrm{P} 4)$, port $12(\mathrm{P} 12)$ and port 8 (P8). The bunkered amount at ports P1, P4, P12 and P8 are 11636, 11472, 10052 and 13407 tons respectively. The second ship starts its voyage from port $1(\mathrm{P} 1)$, then moves to port $2(\mathrm{P} 2)$ and later visits other ports in the following order - P6, P3, P5, P4, P11, P10, P12, P7, P8 and P9. The

bunkering ports of the second vessel pertaining to heavy fuel oil are port 5 (P5) and port 12 (P12). The total amount of heavy fuel oil bunkered at the ports, P5 and P12 are 604.99 tons and 641.42 tons respectively. The ship 2 performs the bunkering of marine diesel oil at four ports port $2(\mathrm{P} 2)$, port $5(\mathrm{P} 5)$, port $10(\mathrm{P} 10)$ and port $8(\mathrm{P} 8)$. The amount bunkered by ship 2 are 11,259 tons at P2, 12,508 tons at P5, 10,942 tons at P10 and 11,228 tons at P8. All the results associated with the vessel 2 are illustrated in Table 5. Table 6 presents the vessel speed, fuel consumption rate, fuel consumed at each leg of the route for both the ships. Travelling time of both the vessels 
while sailing from one port to another and the container flow between two ports or the value of the variable $K_{p q s t c}$ are presented in Table 6.

\subsubsection{Effect of Bad Weather Condition and Port Closure on a Ship Route}

As the disruption events such as weather adversities over certain route or port closure are uncertain in nature, hence it is hard to forecast about the accurate disruptive events. Possible disruptive events can be predicted based on the past data pertaining to different sailing legs and specific ports. The mathematical model considers the possible disruption events which may occur and accordingly provides the shipping company with various options such as vessel route for normal scenario and vessel route for disruption scenarios. Different disruptive scenarios are generated randomly by depicting the realistic scenario for validating the performance of the mathematical model. The model is tested for multiple disruptions on a vessel route associated with bad weather condition, port closure and accordingly its results are presented in table 7.

The port of calls for ship 1 and ship 2 as well as their bunkering ports is known from Tables 4 and 5. The effect of disruption on a sailing leg of the vessel route is studied by considering that the sailing legs between P1 - P2 and P11 - P8 need to be avoided due to poor weather conditions. The sailing legs of the vessel route between P3 - P5 and P12 - P7 are also affected by weather adversities and need to be skipped. Due to such disruptions, the routes for both the vessels should be changed appropriately without affecting the profit and revenue generation of the shipping company. Table 7 presents that ship route under disruption case. To avoid the leg between P1 and P2, ship 1 sails from P1 to P6 and then comes to P2. Similarly, ship 1 travels from P11 to P7 and later moves to P8, thereby avoiding the adverse weather condition between P11 and P8. Reschedule policy is employed to change the route of ship 2 and preventing the vessel from accessing the disrupted legs between P1 - P2, P3 - P5 and P12 - P7. Bunkering cost for heavy fuel oil and carbon tax related to HFO are more in the disruption case as the vessel travels larger distance to change its route and as a result, more fuel (HFO) is consumed. Revenue generated is nearly same as that of the standard scenario as loading and unloading of containers doesn't get affected due to the disruption on various sailing legs. Some of the ports are assumed to be closed on certain time period due to different types of disruptions. Over here, port 2 (P2) and port 12 (P12) are closed in period 3 and period 9 respectively; hence both the vessels need to reschedule their port visits for avoiding the disruptions associated with port closure. Ship 1 
changes its route and sails from port 1 (P1) to port 6 (P6), and after performing its operation at P6 moves to port 2 (P2). Similarly, ship 2 also avoids the closure of port 12 (P12) by visiting port 7 (P7) and later sails back to port 12 (P12). Bunkering cost for heavy fuel oil is more as the vessels need to travel more distances to reschedule its port visits. The model provides different route options to the vessel for normal scenario (no disruptions) and disruptive scenarios (weather adversities and port closure). It can be interpreted from the results that different route options can

help the vessel to change its voyage if faced with certain kind of disruption, yet not hampering its loading/unloading activities at different ports.

Based on the historical data, the possible disruption scenarios are forecasted beforehand and accordingly the solutions (possible ship routes) for normal as well as disrupted scenario are provided to the shipping company. These flexible solutions related to ship routes and also with regard to swapping port visits are then shared with the port authorities. The port authorities generally checks their berth availability and quay crane availability as par the alternate ship route and schedule information (including the port swapping information). Then, they inform the shipping company whether it will be possible for the port to provide a berth to the ship and other necessary equipment for performing port operation or not. And, based on the suggestion of the port authorities, the vessel decides whether to opt for the alternate route option only if met with a specific kind of disruption.

$$
\begin{aligned}
& \text { <<Insert Table 2>> } \\
& <<\text { Insert Table 3>> } \\
& <<\text { Insert Table 4>> } \\
& <<\text { Insert Table 5>> } \\
& <<\text { Insert Table 6>> } \\
& <<\text { Insert Table 7>> }
\end{aligned}
$$

\subsubsection{Impact of Bunkering Capacities and Bunker Fuel Prices}

The effect of changing the bunker fuel capacity for marine diesel oil (MDO) and heavy fuel oil (HFO) is studied. Various bunker fuel management strategies and their corresponding bunker fuel costs under different bunker fuel capacities are presented in Table 8. For the normal scenario, the partial bunkering capacity for HFO and MDO are 1000 ton and 2000 ton respectively. Certain times vessels perform partial bunkering of fuel at the port as it aim to travel 
with less amount of fuel for reducing the inventory cost. Three different scenarios related to the bunkering capacity for HFO and MDO are considered: (1) partial bunkering capacities for HFO and MDO are 1000 ton each, (2) partial bunkering capacities for HFO and MDO are 2000 ton each, and (3) full bunkering capacities for HFO and MDO are 3000 ton each. It can be interpreted from the table that by increasing the bunkering capacity of the ship, the number of times bunkering performed is less in the second case as compared to the first case. Hence, overall bunkering costs for marine diesel oil (MDO) and heavy fuel oil (HFO) in the second case are less than that of the first case. If the bunker capacity for both the fuel is increased from 1000 to 2000 ton, then the bunker fuel related cost for MDO and HFO decreases from USD 3,760,915.01 to USD 3,398,615.27 (i.e. - USD 362,299.74, - 9.63\%) and USD 625,949.97 to USD 538,697.92 (i.e. - USD 87252.05, - 13.93\%) respectively. The main reason behind this reduction is the lesser number of bunkering ports for heavy fuel oil (from two to one for ship 1 as well as ship 2) and marine diesel oil (from three to one for ship 1 and three to two for ship 2). It is noted that the fixed bunkering cost is less in the second scenario due to the lesser number of bunkering ports. In the third scenario, the vessels don't require to perform the bunkering of heavy fuel oil as the bunkering capacity is enough to sustain for the overall planning horizon and the cost associated with bunkering HFO is zero. Bunkering cost of MDO in the third scenario is lower than that of the other scenarios due to the lesser number of bunkering ports and the overall bunkered amount is also less for both the ships. Table 8 presents the bunker fuel management strategies under different scenarios. Profit incurred for the shipping company increases with the increase in bunkering capacity because the bunkered amount and the bunkering cost decreases with the increase in bunkering capacity of the ship for different types of fuel.

The effect of bunker fuel prices is studied by considering different scenarios of fuel prices for marine diesel oil (MDO) and heavy fuel oil (HFO). Five different scenarios are considered: (1) fuel prices for MDO and HFO remain unchanged, (2) increasing the fuel prices for both MDO and HFO by 25\%, (3) decreasing the fuel prices for both MDO and HFO by 25\%, (4) fuel prices for MDO increased by $25 \%$ and fuel prices for HFO decreased by $25 \%$, and (5) fuel prices for MDO decreased by $25 \%$ and fuel prices for HFO increased by $25 \%$. For a fair comparison, the bunkering capacities for MDO and HFO are considered as 1500 tons each for all the five scenarios. Table 9 presents the bunker fuel management strategies related to bunkering ports and bunkering amounts for different fuel pricing scenarios. Fluctuating bunker fuel prices at several 
ports affect the selection of bunkering ports for MDO and HFO. The port with lowest bunker fuel price may not be a bunkering port for the ship as the bunker fuel requirement keeps changing for different legs of the service route. The bunkering costs for marine diesel oil and heavy fuel oil are affected by the variations in the bunker fuel prices. As the bunker prices increase, the bunkering cost for both types of fuel also increase, and as a result, the profit incurred decreases. When the bunker prices for marine diesel oil and heavy fuel oil are reduced by $25 \%$ (scenario 3), the bunkering cost for HFO and MDO also decreases as compared to the result of scenario 1 and 2. Due to the reduction in the cost components, the profit associated with the scenario 3 increases when compared with that of scenario 1 and 2. Profit incurred for scenario 4 decreases when compared to scenario 1 and 3, as the marine diesel oil bunkering cost increases with the $25 \%$ increment in the fuel price of MDO. Bunkering cost for MDO for scenario 5 decreases substantially when compared with scenario 1 as the MDO fuel price is decreased by $25 \%$ in scenario 5. Profit associated with scenario 5 and scenario 3 is much better than that of scenario 1 as the bunker fuel (MDO) price for scenario 5 and 3 is reduced by $25 \%$ leading to a reduction in the MDO bunkering cost for both the scenarios.

\subsubsection{Effect of Carbon Tax and Fuel Consumption rate}

The effect of variations in the profit is studied in this section considering the changes in the carbon tax and vessel fuel consumption rate while at port and sea. The range of vessel speed is considered between $14-18$ knots instead of $14-24$ knots to reduce the consumption of heavy fuel oil. The marine diesel oil consumed per hour by the vessel while operating at the port is also changed and its impact on the profit incurred is estimated. Three different scenarios are considered to study the effect of a change in the carbon tax and fuel consumption rate for both types of fuel on the total profit. For all the different scenarios, the vessel speed is considered within the range of $14-18$ knots. Three scenarios are: (1) carbon tax and fuel consumption rate at the port are kept unchanged, (2) carbon tax and fuel consumption rate at the port are decreased by $50 \%$, and (3) carbon tax and fuel consumption rate at the port are increased by 50\%. Table 10 presents the sensitivity analysis pertaining to the variation in the carbon tax and fuel consumption rate at the port. As the vessel speed for the three scenarios is considered within a particular range of $14-18$ knots, hence the fuel consumption for the ship while sailing in the sea is much lesser. Although, slowing down the vessels will also increase the sailing time of the ship between two ports which may hamper the overall voyage time. It can be depicted from Table 10 
that lowering the carbon tax by 50\%, decreases the carbon tax associated with marine diesel oil and heavy fuel oil from USD 840,184.02 to USD 231,150 (i.e. - USD 609,034.02, -72.48\%) and USD 291,530.70 to USD 143,800.69 (i.e. - USD 147,730.01, - 50.67\%) respectively. Carbon tax related to marine diesel oil reduced to a larger amount due to the lowering of the fuel consumption rate (tons per hour) at the port by $50 \%$. Reduction in the carbon tax for both types of fuels has a bigger impact on the profit incurred as it increases from USD 28,867,713.55 to USD 31,511,561.99 (i.e. USD 2,643,848.44, 9.15\%). Hence, it is essential to prefer fuel efficient vessels than older/inefficient ones as it provides relatively lower fuel consumption rates at the port. With the increase in the carbon tax and fuel consumption rate, the carbon tax associated with both types of fuels increases substantially, owing to a reduction in the total amount of profit incurred.

$$
\begin{aligned}
& \text { << Insert Table 8>> } \\
& \text { <<Insert Table 9>> } \\
& <<\text { Insert Table 10>> }
\end{aligned}
$$

\subsection{Result Analysis}

The results associated with problem instances 2, 3, 4 and 5 such as revenue generated, cost related to container loading and unloading, fixed cost for performing port operation, bunkering cost for marine diesel oil (MDO) and heavy fuel oil (HFO), fixed cost for carrying out bunkering and carbon tax associated with both types of fuels are presented in Table 3. Observation from Table 3 highlights the fact that the majority of the cost for the shipping company comprises of the bunkering cost for marine diesel oil. The increase in the supply and demand at supply and demand ports increases the revenue generated for the shipping company, whereas it also increases the cost components as more vessels are employed for the service. Deploying of more numbers of ships increases the overall carbon emission, leading to an increment in the carbon tax. The slow steaming policy helps to reduce the fuel consumption, bunkering cost and carbon tax associated with HFO. The fuel cost might be higher for certain shipping companies which are still not in favour of incorporating sustainable strategies. The values obtained for ship routes, vessel speed on each leg, bunkering ports, bunkered amount for MDO and HFO for some of the problem instances are illustrated in Table 11. The additional information presented in Table 11 provides an idea about the output of the mathematical model regarding the vessel route, ship speed and their bunkering strategies. Ship 1 of the first problem instance performs the bunkering 
of MDO at port 4 and port 9 and bunkering of HFO at three ports - port 4, port 13 and port 16 . Bunkering strategies associated with all the ships are mentioned in the table along with other information related to the vessel speed on different sailing legs.

\section{$<<$ Insert Table 11 >>}

\subsection{Managerial Implications}

Shipping companies compromise on the fuel consumption for reaching early to the port in order to meet the demand within the allotted time as they aim to earn more revenue. Although, for increasing the profitability the shipping company managers also need to investigate about the cost components of the shipping companies such as bunkering cost related to different types of fuel and carbon tax which can be lowered by adopting different policies. The result obtained out of this work provides useful information to the shipping company managers stating that the reduction in the bunkering costs for marine diesel oil and heavy fuel oil has a greater impact in increasing the total profit incurred by the shipping company. Hence, it is essential for the shipping company managers to simultaneously re-design their vessels route, determining the ideal bunkering ports and estimating the bunkering amounts for different types of fuels as it is imperative to perform the bunkering at ports with lower bunker fuel price for lowering the overall operational cost. Therefore, fuel prices and bunkering capacities need to be reconsidered by the shipping company managers while selecting the bunkering ports and bunkering amounts. From the results, it can be informed to the shipping company managers that designing of ship route should be performed by giving prior importance to the ports having lower fuel price such that the vessel can easily visit these ports when there is an urgent need of fuel bunkering. The vessels with slightly more bunker fuel in their tank travel to ports with lower bunker fuel prices for performing their bunkering and thereby incurring lesser bunkering cost. It can also be notified to the shipping company managers that if their vessel has to visit fewer numbers of ports, then it can opt for partial bunkering fuel capacity and thereby reduce the overall operational cost.

For avoiding the weather adversities, shipping company managers can be advised that their vessels can opt for strategies such as port swapping and rescheduling their route. The results from the mathematical model provide various options to the shipping company managers in terms of having several route options for their vessels pertaining to different port of calls for normal scenario (no disruptions) and disrupted scenarios (which include weather adversities on 
sailing leg or port closure). As disruption scenarios are uncertain in nature, hence it is mandatory for the shipping company managers to possess different alternatives which might help them to change the voyage of their vessel when faced with weather adversities or port closure related disruptions. It is interpreted from the result that reducing the ship speed range may lead to lowering of the bunker fuel consumption or decrease in the fuel cost and simultaneously increase the profit. Although, changing the course of the vessel for avoiding the disrupted sailing leg may lead to increase in fuel consumption as more distances need to be covered by the vessel. In such scenarios, shipping company managers may look to reduce their vessel's speed for lowering the fuel consumption and thus reducing its carbon tax. Although, reduction of the ship speed increases the traveling time of the vessel between two ports and it may lead to delay in meeting the demand of the customer.

Hence, the shipping company managers should focus on maintaining an ideal trade-off between the fuel consumption while sailing and travelling time of the vessel as fuel cost incurred should be within an acceptable limit and delivery of the containers to their customers should be performed in a timely manner. Vessels may look to reduce their speed when the carbon tax rate is higher, and it will enable them to mitigate the overall carbon tax incurred for the shipping company.

\section{Conclusion}

In this research work, a problem of sustainable container shipping operation along with bunker fuel management is studied. Disruptive scenarios such as port closure, weather adversities, etc. are taken in account while addressing the problem. A mathematical formulation is developed to maximize the profit incurred for the shipping company by increasing the revenue generated and lowering the fuel bunkering cost, loading and unloading cost and carbon tax related costs. Bunkering decisions such as selection of bunkering ports and the amount of fuel to be bunkered at a port are taken into consideration for two types of fuels - marine diesel oil (MDO) and heavy fuel oil (HFO). Given that the complex nature of the problem a mathematical model based heuristic combined with variable neighborhood search (VNS) algorithm is proposed in the paper. As VNS algorithm is quite powerful and provides superior results while solving a variety of combinatorial optimization problems compared to other benchmark algorithms [32], hence the choice of combining the proposed heuristic with VNS is justified. An illustrative example is 
provided to realise the output deliverables of the mathematical model and study the effect of disruptions in shipping, bunker fuel prices, bunkering capacities and carbon tax through sensitivity analysis. The research work aims to provide valuable insights to the shipping company managers in terms of providing them with various alternatives related to vessel route for normal scenario (no disruption) and disruption scenario (weather related adversities or port closure). Moreover, this research helps the shipping company managers to understand the relationship between vessel route and schedule design with the bunker fuel management decisions. One of the important managerial implications which can be drawn from the results is the importance of performing the vessel route and schedule design while determining the bunkering ports and bunkering amounts. This would help the shipping company managers to reduce their fuel bunkering cost and in turn lower the overall operational cost.

In future work, a stochastic demand, supply and bunker fuel prices can be included in the problem to make it closer to the practical scenario. Other disruptive events such as vessel engine breakdown, port congestion related aspects need to be taken into consideration for addressing various practicalities within maritime transportation domain. The problem can be extended by considering different sizes of vessels and incorporate fuel consumption and vessel speed relationships associated with vessel sizes. The uncertainties related to the disruptive events can be captured in the problem by incorporating the probabilistic nature of the unpredictable emergency events [38].

\section{References}

[1] A. De, A. Choudhary, and M. K. Tiwari, "Multiobjective Approach for Sustainable Ship Routing and Scheduling With Draft Restrictions," IEEE Trans. Eng. Manag., 2017.

[2] A. De, V. K. R. Mamanduru, A. Gunasekaran, N. Subramanian, and M. K. Tiwari, "Composite particle algorithm for sustainable integrated dynamic ship routing and scheduling optimization," Comput. Ind. Eng., vol. 96, pp. 201-215, 2016.

[3] E. Y. C. Wong, A. H. Tai, H. Y. K. Lau, and M. Raman, "An utility-based decision support sustainability model in slow steaming maritime operations," Transp. Res. Part E Logist. Transp. Rev., vol. 78, pp. 57-69, 2015.

[4] A. De, S. K. Kumar, A. Gunasekaran, and M. K. Tiwari, "Sustainable maritime inventory routing problem with time window constraints," Eng. Appl. Artif. Intell., vol. 61, pp. 77-95, 2017. 
[5] N. Aydin, H. Lee, and S. A. Mansouri, "Speed optimization and bunkering in liner shipping in the presence of uncertain service times and time windows at ports," Eur. J. Oper. Res., vol. 259, no. 1, pp. 143-154, 2017.

[6] D. Ronen, "The effect of oil price on containership speed and fleet size," J. Oper. Res. Soc., vol. 62, no. 1, pp. 211-216, 2011.

[7] J. Xia, K. X. Li, H. Ma, and Z. Xu, "Joint planning of fleet deployment, speed optimization, and cargo allocation for liner shipping,” Transp. Sci., vol. 49, no. 4, pp. 922-938, 2015.

[8] O. Besbes and S. Savin, "Going bunkers: the joint route selection and refueling problem," Manuf. Serv. Oper. Manag., vol. 11, no. 4, pp. 694-711, 2009.

[9] Q. Meng, S. Wang, and C.-Y. Lee, "A tailored branch-and-price approach for a joint tramp ship routing and bunkering problem," Transp. Res. Part B Methodol., vol. 72, pp. 1-19, 2015.

[10] C. Li, X. Qi, and D. Song, "Real-time schedule recovery in liner shipping service with regular uncertainties and disruption events," Transp. Res. Part B Methodol., vol. 93, pp. 762-788, 2016.

[11] B. D. Brouer, J. Dirksen, D. Pisinger, C. E. M. Plum, and B. Vaaben, "The Vessel Schedule Recovery Problem (VSRP)--A MIP model for handling disruptions in liner shipping," Eur. J. Oper. Res., vol. 224, no. 2, pp. 362-374, 2013.

[12] A. Agra, M. Christiansen, and A. Delgado, "Mixed integer formulations for a short sea fuel oil distribution problem," Transp. Sci., vol. 47, no. 1, pp. 108-124, 2013.

[13] R. Rocha, I. E. Grossmann, and M. V. S. P. de Aragão, "Cascading knapsack inequalities: reformulation of a crude oil distribution problem," Ann. Oper. Res., vol. 203, no. 1, pp. 217-234, 2013.

[14] J. G. Rakke, H. Andersson, M. Christiansen, and G. Desaulniers, "A new formulation based on customer delivery patterns for a maritime inventory routing problem," Transp. Sci., vol. 49, no. 2, pp. 384-401, 2014.

[15] B.-C. Choi, K. Lee, J. Y.-T. Leung, M. L. Pinedo, and D. Briskorn, "Container scheduling: Complexity and algorithms," Prod. Oper. Manag., vol. 21, no. 1, pp. 115-128, 2012.

[16] J.-H. Song and K. C. Furman, "A maritime inventory routing problem: Practical approach," Comput. Oper. Res., vol. 40, no. 3, pp. 657-665, 2013.

[17] J. de Armas, E. Lalla-Ruiz, C. Expósito-Izquierdo, D. Landa-Silva, and B. Melián-Batista, "A hybrid GRASP-VNS for ship routing and scheduling problem with discretized time windows," Eng. Appl. Artif. Intell., vol. 45, pp. 350-360, 2015.

[18] K. Fagerholt, N. T. Gausel, J. G. Rakke, and H. N. Psaraftis, "Maritime routing and speed optimization with emission control areas," Transp. Res. Part C Emerg. Technol., vol. 52, pp. 57$73,2015$. 
[19] Z. Yao, S. H. Ng, and L. H. Lee, "A study on bunker fuel management for the shipping liner services," Comput. Oper. Res., vol. 39, no. 5, pp. 1160-1172, 2012.

[20] S. Wang and Q. Meng, "Robust bunker management for liner shipping networks," Eur. J. Oper. Res., vol. 243, no. 3, pp. 789-797, 2015.

[21] Q. Meng, S. Wang, H. Andersson, and K. Thun, "Containership routing and scheduling in liner shipping: overview and future research directions," Transp. Sci., vol. 48, no. 2, pp. 265-280, 2013.

[22] J. Guan and G. Lin, "Hybridizing variable neighborhood search with ant colony optimization for solving the single row facility layout problem," Eur. J. Oper. Res., vol. 248, no. 3, pp. 899-909, 2016.

[23] P. P. Repoussis, C. D. Tarantilis, O. Bräysy, and G. Ioannou, "A hybrid evolution strategy for the open vehicle routing problem," Comput. Oper. Res., vol. 37, no. 3, pp. 443-455, 2010.

[24] S. A. MirHassani and N. Abolghasemi, "A particle swarm optimization algorithm for open vehicle routing problem,” Expert Syst. Appl., vol. 38, no. 9, pp. 11547-11551, 2011.

[25] A. Jabbarzadeh, B. Fahimnia, and S. Rastegar, "Green and Resilient Design of Electricity Supply Chain Networks: A Multiobjective Robust Optimization Approach," IEEE Trans. Eng. Manag., no. 99, pp. 1-21, 2017.

[26] X. Li and S. Ma, "Multiobjective discrete artificial bee colony algorithm for multiobjective permutation flow shop scheduling problem with sequence dependent setup times," IEEE Trans. Eng. Manag., vol. 64, no. 2, pp. 149-165, 2017.

[27] A. Hemmati, L. M. Hvattum, M. Christiansen, and G. Laporte, "An iterative two-phase hybrid matheuristic for a multi-product short sea inventory-routing problem," Eur. J. Oper. Res., vol. 252, no. 3, pp. 775-788, 2016.

[28] L. Zhen, S. Wang, and D. Zhuge, "Dynamic programming for optimal ship refueling decision," Transp. Res. Part E Logist. Transp. Rev., vol. 100, pp. 63-74, 2017.

[29] B. Jarboui, H. Derbel, S. Hanafi, and N. Mladenović, "Variable neighborhood search for location routing," Comput. Oper. Res., vol. 40, no. 1, pp. 47-57, 2013.

[30] S. Belhaiza, P. Hansen, and G. Laporte, "A hybrid variable neighborhood tabu search heuristic for the vehicle routing problem with multiple time windows," Comput. Oper. Res., vol. 52, pp. 269$281,2014$.

[31] N. Mladenović, R. Todosijević, and D. Urošević, "Two level general variable neighborhood search for attractive traveling salesman problem," Comput. Oper. Res., vol. 52, pp. 341-348, 2014.

[32] N. Wassan, N. Wassan, G. Nagy, and S. Salhi, "The Multiple trip vehicle routing problem with backhauls: Formulation and a two-level variable neighbourhood search," Comput. Oper. Res., vol. 78, pp. 454-467, 2017. 
[33] C. Barnhart and G. Laporte, Handbooks in Operations Research and Management Science: Volume 14, Transportation. Elsevier Science \& Technology, 2007.

[34] C.-I. HSU and Y.-P. HSIEH, "Shipping economic analysis for ultra large containership," J. East. Asia Soc. Transp. Stud., vol. 6, pp. 936-951, 2005.

[35] A. De, J. Wang and M. K. Tiwari. "Hybridizing basic variable neighborhood search with particle swarm optimization for solving sustainable ship routing and bunker management problem." IEEE Transactions on Intelligent Transportation Systems (2019), DOI 10.1109/TITS.2019.2900490.

[36] A. De, S. Pratap, A. Kumar, and M. K. Tiwari. "A hybrid dynamic berth allocation planning problem with fuel costs considerations for container terminal port using chemical reaction optimization approach." Annals of Operations Research (2018): 1-29.

[37] A. De, A. Awasthi, and M. K. Tiwari. "Robust formulation for optimizing sustainable ship routing and scheduling problem." IFAC-PapersOnLine 48, no. 3 (2015): 368-373.

[38] Y.M. Zhou, J.W. Wang, and H. Yang. " Resilience of transportation systems - concepts and comprehensive review." IEEE Transactions on Intelligent Transportation Systems (2019), DOI:c10.1109/TITS.2018.2883766. 


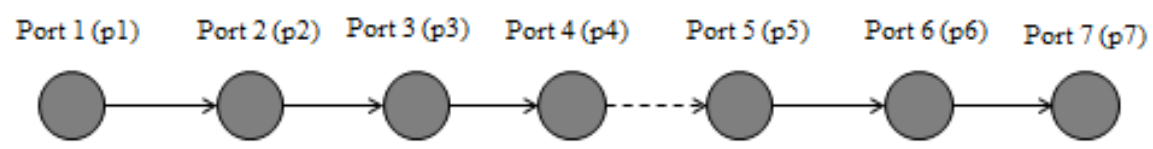

Case 1
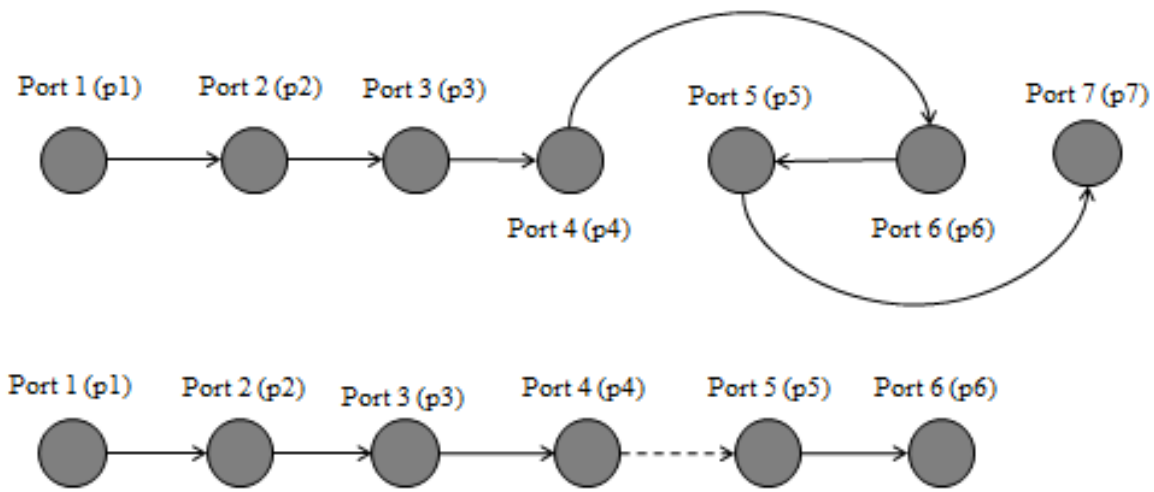

Case 2

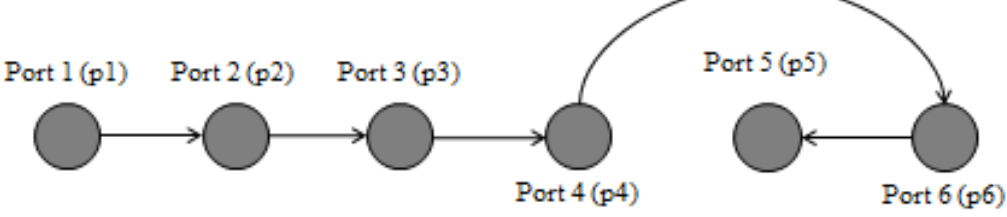

Figure 1: Reschedule of the vessel route due to the disruption
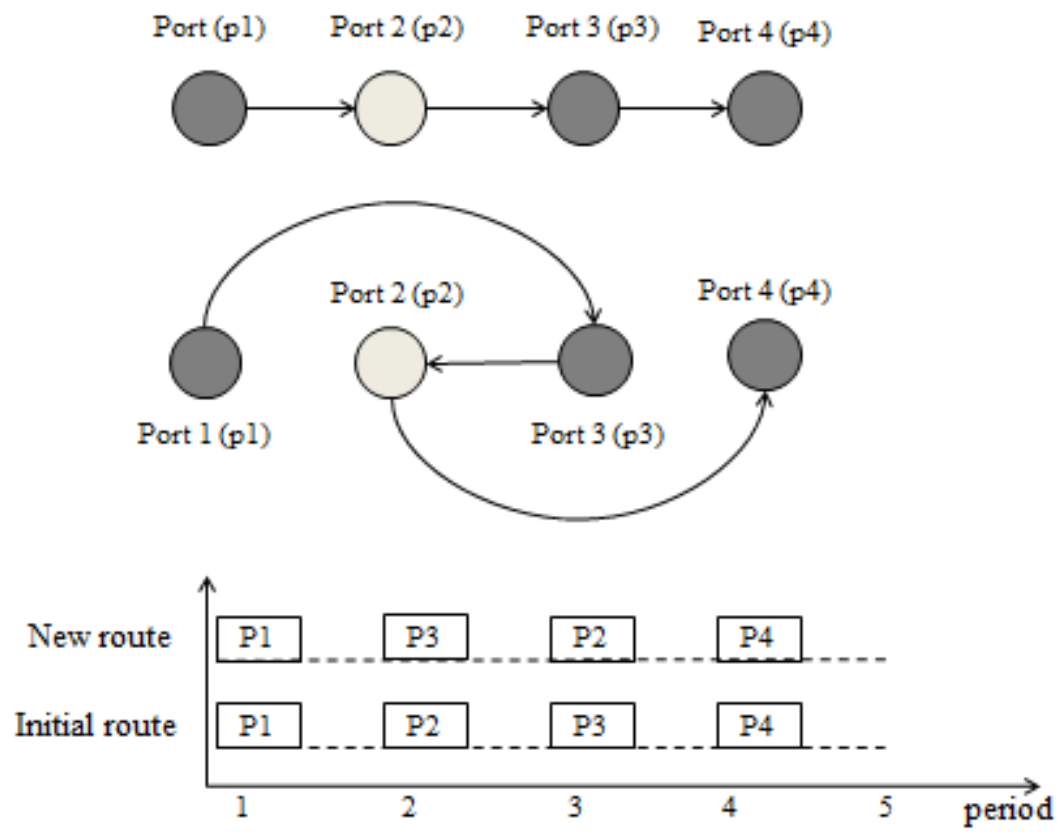

Figure 2: Rescheduling the vessel route due to the closure of a specific port 


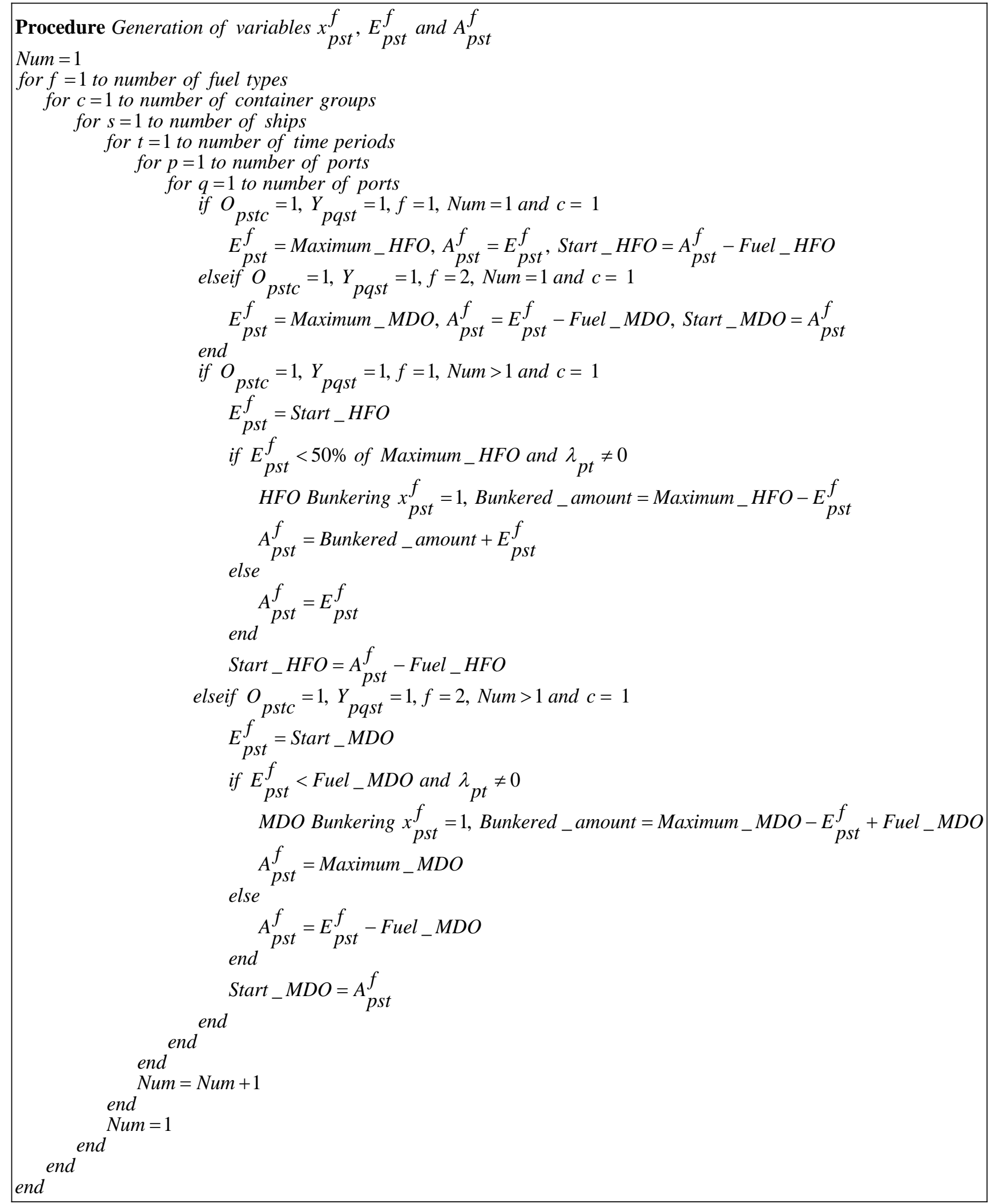

Figure 3: Algorithm for determining the bunkering decisions for heavy fuel oil and marine diesel oil 


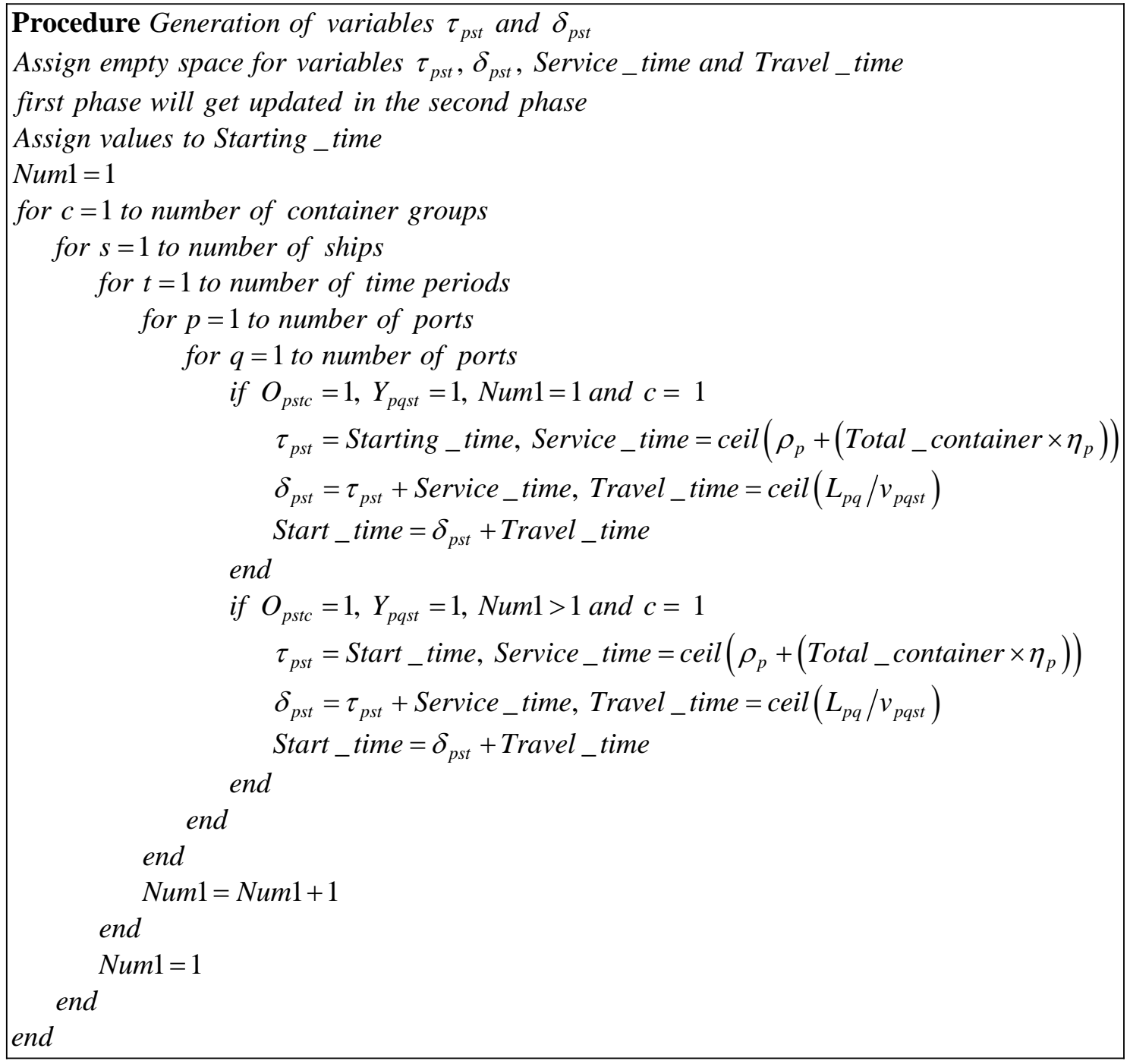

Figure 4: Pseudo code for determining the arrival and departure time of the vessel at a port 


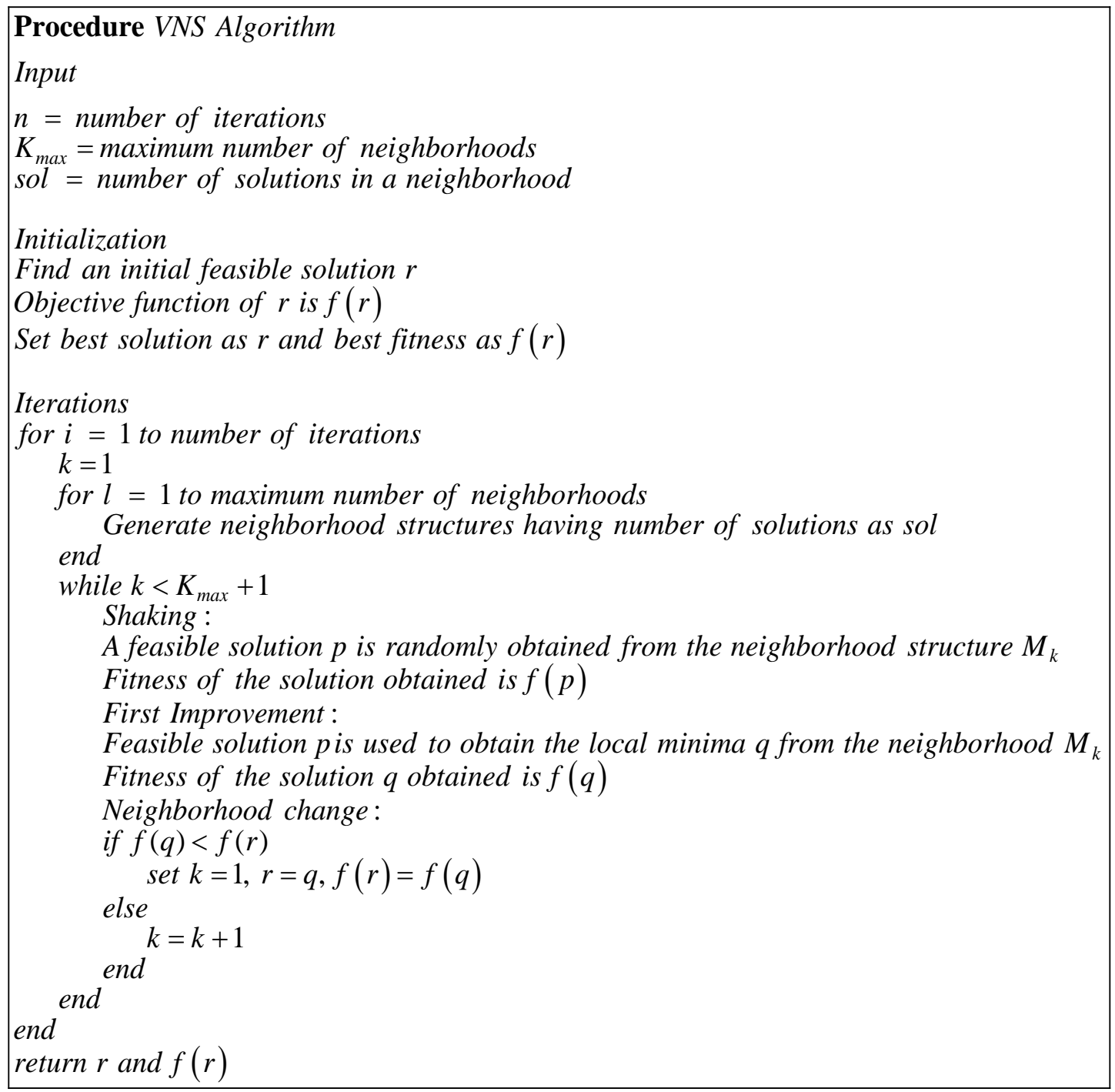

Figure 5: Pseudo-code of the variable neighborhood search algorithm

Position of the variables in the neighbourhood structure

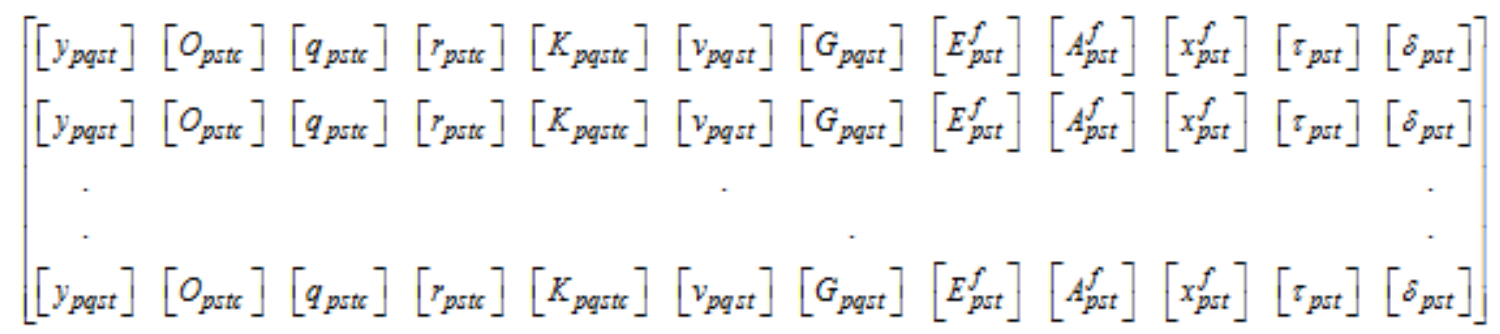

Figure 6: Neighborhood structure of the VNS algorithm comprising of different variables 
Table 1: Different problem instances for the experimental purpose

\begin{tabular}{|c|c|c|c|c|c|}
\hline $\begin{array}{c}\text { Serial } \\
\text { No. }\end{array}$ & $\begin{array}{c}\text { Problem Instance } \\
\text { (supply ports, demand ports, } \\
\text { periods, containers, ships, fuel } \\
\text { types) }\end{array}$ & $\begin{array}{c}\text { No. of } \\
\text { variables }\end{array}$ & $\begin{array}{c}\text { No. of } \\
\text { equality } \\
\text { constraints }\end{array}$ & $\begin{array}{c}\text { No. of } \\
\text { inequality } \\
\text { constraints }\end{array}$ & $\begin{array}{c}\text { Total } \\
\text { number of } \\
\text { constraints }\end{array}$ \\
\hline 1 & $(6,6,14,2,2,2)$ & 24,192 & 68,884 & 69,914 & 138,798 \\
\hline 2 & $(8,8,18,2,4,2)$ & 105,984 & 381,320 & 386,532 & 767,852 \\
\hline 3 & $(10,10,25,2,6,2)$ & 336,000 & $1,651,012$ & $1,666,046$ & $3,317,058$ \\
\hline 4 & $(12,12,30,2,8,2)$ & 760,320 & $4,481,296$ & $4,511,576$ & $8,992,872$ \\
\hline 5 & $(15,15,40,2,10,2)$ & $1,944,000$ & $15,240,020$ & $15,302,470$ & $30,542,490$ \\
\hline
\end{tabular}

Table 2: Data for the parameters of the mathematical model

\begin{tabular}{|c|c|c|}
\hline Parameter & Range & Units \\
\hline Revenue generated for transporting a container, $A_{p q c}$ & $(500,1000)$ & USD/container \\
\hline Loading and unloading cost of a container, $H_{p c}$ & $(50,100)$ & USD/container \\
\hline Cost for performing operation at a port, $E_{p t}^{o p e r}$ & $(500,1000)$ & USD/operation \\
\hline Heavy fuel oil (HFO) price at a port, $E_{p t}^{H F O}$ & $(220,320)$ & USD/ton \\
\hline Marine diesel oil price at a port, $E_{p t}^{M D O}$ & $(450,600)$ & USD/ton \\
\hline Marine diesel oil consumed by the vessel at port, $g_{p s t}$ & $(2,4)$ & Ton/Hours (real time) \\
\hline Fixed cost for performing bunkering of fuel, $\pi_{p}^{f}$ & $(500,600)$ & USD/ bunkering \\
\hline Supply of different container group at supply port, $G_{p c}$ & $(600,700)$ & Units \\
\hline Demand of different container group at demand port, $D_{p c}$ & $(500,600)$ & Units \\
\hline Maximum capacity of a ship, $M_{s}$ & $(350,400)$ & Units \\
\hline Distance between two ports, $L_{p q}$ & $(500,600)$ & Nautical miles (nm) \\
\hline Set up time for performing port operation, $\rho_{p}$ & $(0.5,1)$ & Hours per operation \\
\hline Loading or unloading time of a container at a port, $\eta_{p c}$ & $(0.2,0.3)$ & Hours per operation \\
\hline Numbers of berths available at a port, $B_{p t}$ & $(3,5)$ & Berths \\
\hline
\end{tabular}


Table 3: Profit incurred, revenue generated and values pertaining to the cost components for all the problem instances

\begin{tabular}{|c|c|c|c|c|c|c|c|c|c|c|}
\hline \multirow{2}{*}{$\begin{array}{l}\text { Problem Instance } \\
\text { (supply ports, } \\
\text { demand ports, } \\
\text { periods, } \\
\text { containers, ships, } \\
\text { fuel types) }\end{array}$} & \multirow[t]{2}{*}{ Profit (USD) } & \multirow{2}{*}{$\begin{array}{c}\text { Revenue } \\
\text { generated } \\
\text { (USD) }\end{array}$} & \multicolumn{8}{|c|}{ Cost components (USD) } \\
\hline & & & $\begin{array}{l}\text { Container } \\
\text { loading } \\
\text { cost }\end{array}$ & $\begin{array}{l}\text { Container } \\
\text { unloading } \\
\text { cost }\end{array}$ & $\begin{array}{l}\text { Fixed cost } \\
\text { required for } \\
\text { port } \\
\text { operation }\end{array}$ & $\begin{array}{c}\text { Fuel (HFO) } \\
\text { bunkering } \\
\text { cost }\end{array}$ & $\begin{array}{c}\text { Fuel (MDO) } \\
\text { bunkering } \\
\text { cost }\end{array}$ & $\begin{array}{c}\text { Fixed cost } \\
\text { for } \\
\text { bunkering }\end{array}$ & $\begin{array}{l}\text { Carbon tax } \\
\text { for } \\
\text { consuming } \\
\text { MDO }\end{array}$ & $\begin{array}{l}\text { Carbon tax } \\
\text { for } \\
\text { consuming } \\
\text { HFO }\end{array}$ \\
\hline$(6,6,14,2,2,2)$ & $26,523,252.83$ & $34,051,896$ & 520,202 & 429,062 & 35,240 & $689,267.87$ & $4,653,659.96$ & 4,482 & $890,944.56$ & $305,784.75$ \\
\hline$(8,8,18,2,4,2)$ & $105,280,511.07$ & $122,133,521$ & $1,295,010$ & $1,102,107$ & 97,480 & $1,866,166.52$ & $9,568,042.45$ & 11,223 & $2,091,075.36$ & $821,905.57$ \\
\hline $\begin{array}{c}(10,10,25,2,6 \\
2)\end{array}$ & $160,986,076.15$ & $186,124,742$ & $1,631,450$ & $1,354,726$ & 179,098 & $3,899,116.97$ & $13,650,225.77$ & 19,649 & $2,843,237.46$ & $1,561,162.63$ \\
\hline $\begin{array}{c}(12,12,30,2,8 \\
2)\end{array}$ & $471,265,512.31$ & $530,685,279$ & $4,134,628$ & $3,482,683$ & 284,694 & $6,654,217.64$ & $35,349,165.58$ & 38,767 & $6,961,683.24$ & $2,513,928.20$ \\
\hline $\begin{array}{c}(15,15,40,2,10, \\
2)\end{array}$ & $940,270,297.95$ & $1,035,107,552$ & $6,113,422$ & $5,505,388$ & 448,048 & $11,461,806.45$ & $56,477,428.46$ & 64,566 & $10,794,057.78$ & $3,972,537.34$ \\
\hline
\end{tabular}

Table 4: Results associated with the first ship of the illustrative example

\begin{tabular}{|c|c|c|c|c|c|c|c|c|c|c|c|c|c|c|c|c|}
\hline \multirow[t]{2}{*}{$\begin{array}{l}\text { Port } \\
\text { visit }\end{array}$} & \multirow{2}{*}{$\begin{array}{c}\text { Arrival } \\
\text { time } \\
\text { (hours) }\end{array}$} & \multirow{2}{*}{$\begin{array}{c}\text { Departure } \\
\text { time } \\
\text { (hours) }\end{array}$} & \multirow{2}{*}{$\begin{array}{c}\text { Service } \\
\text { time at } \\
\text { port } \\
\text { (hours) }\end{array}$} & \multirow{2}{*}{$\begin{array}{c}\text { HFO } \\
\text { inventory } \\
\text { while } \\
\text { arriving } \\
\text { (ton) }\end{array}$} & \multirow{2}{*}{$\begin{array}{c}\text { HFO } \\
\text { inventory } \\
\text { while } \\
\text { departure } \\
\text { (ton) }\end{array}$} & \multirow{2}{*}{$\begin{array}{l}\text { MDO } \\
\text { inventory } \\
\text { while } \\
\text { arriving } \\
\text { (ton) }\end{array}$} & \multirow{2}{*}{$\begin{array}{l}\text { MDO } \\
\text { inventory } \\
\text { while } \\
\text { departure } \\
\text { (ton) }\end{array}$} & \multicolumn{2}{|c|}{$\begin{array}{c}\text { Bunkering } \\
\text { ports }\end{array}$} & \multicolumn{2}{|c|}{$\begin{array}{c}\text { Bunkered } \\
\text { amount (ton) }\end{array}$} & \multirow{2}{*}{$\begin{array}{c}\text { MDO } \\
\text { consumed } \\
\text { (ton) }\end{array}$} & \multicolumn{2}{|c|}{$\begin{array}{c}\text { Container } \\
\text { Loaded (units) }\end{array}$} & \multicolumn{2}{|c|}{$\begin{array}{c}\text { Container } \\
\text { Unloaded (units) }\end{array}$} \\
\hline & & & & & & & & $\mathrm{HFO}$ & MDO & HFO & MDO & & $\begin{array}{l}\text { Container } \\
\text { group } 1\end{array}$ & $\begin{array}{l}\text { Container } \\
\text { group } 2\end{array}$ & $\begin{array}{l}\text { Container } \\
\text { group } 1\end{array}$ & $\begin{array}{l}\text { Container } \\
\text { group } 2\end{array}$ \\
\hline P5 & 10 & 169 & 159 & 1000 & 1000 & 2000 & 1494.6 & - & - & - & - & 505.38 & 275 & 296 & - & - \\
\hline P1 & 196 & 365 & 169 & 856.4 & 856.4 & 1494.6 & 1197.1 & - & - & - & - & 297.48 & 329 & 249 & - & - \\
\hline $\mathrm{P} 2$ & 394 & 580 & 186 & 692.9 & 692.9 & 1197.1 & 517 & - & - & - & - & 680.18 & 311 & 326 & - & - \\
\hline P6 & 605 & 714 & 109 & 543.3 & 543.3 & 517 & 260 & - & - & - & - & 256.99 & 247 & 283 & - & - \\
\hline P4 & 739 & 870 & 131 & 368.9 & 1000 & 260 & 2000 & $\mathrm{P} 4$ & $\mathrm{P} 4$ & 631.11 & 2331.3 & 591.27 & 243 & 307 & - & - \\
\hline P3 & 896 & 1059 & 163 & 832 & 832 & 2000 & 1589.9 & - & - & - & - & 410.09 & 301 & 290 & - & - \\
\hline P12 & 1081 & 1207 & 126 & 674.7 & 674.9 & 1589.9 & 1172.1 & - & - & - & - & 417.81 & - & - & 259 & 246 \\
\hline P9 & 1231 & 1361 & 130 & 517.4 & 517.4 & 1172.1 & 974.9 & - & - & - & - & 197.19 & - & - & 235 & 284 \\
\hline P11 & 1394 & 1512 & 118 & 372 & 1000 & 974.9 & 682.6 & P11 & - & 627.98 & - & 292.31 & - & - & 202 & 256 \\
\hline P8 & 1546 & 1693 & 147 & 865.6 & 865.6 & 682.6 & 310.2 & - & - & - & - & 372.33 & - & - & 232 & 262 \\
\hline P7 & 1722 & 1828 & 106 & 702.6 & 702.6 & 310.2 & 2000 & - & P7 & - & 2113.4 & 423.62 & - & - & 211 & 231 \\
\hline P10 & 1854 & 1970 & 116 & 564.2 & 564.2 & 2000 & 1599.7 & - & - & - & - & 400.33 & - & - & 256 & 223 \\
\hline
\end{tabular}


Table 5: Results associated with the second ship of the illustrative example

\begin{tabular}{|c|c|c|c|c|c|c|c|c|c|c|c|c|c|c|c|c|}
\hline \multirow[t]{2}{*}{$\begin{array}{l}\text { Port } \\
\text { visit }\end{array}$} & \multirow{2}{*}{$\begin{array}{l}\text { Arrival } \\
\text { time } \\
\text { (hours) }\end{array}$} & \multirow{2}{*}{$\begin{array}{c}\text { Departure } \\
\text { time } \\
\text { (hours) }\end{array}$} & \multirow{2}{*}{$\begin{array}{c}\text { Service } \\
\text { time at } \\
\text { port } \\
\text { (hour) }\end{array}$} & \multirow{2}{*}{$\begin{array}{c}\text { HFO } \\
\text { inventory } \\
\text { while } \\
\text { arriving } \\
\text { (ton) } \\
\end{array}$} & \multirow{2}{*}{$\begin{array}{c}\text { HFO } \\
\text { inventory } \\
\text { while } \\
\text { departure } \\
\text { (ton) } \\
\end{array}$} & \multirow{2}{*}{$\begin{array}{l}\text { MDO } \\
\text { inventory } \\
\text { while } \\
\text { arriving } \\
\text { (ton) }\end{array}$} & \multirow{2}{*}{$\begin{array}{c}\text { MDO } \\
\text { inventory } \\
\text { while } \\
\text { departure } \\
\text { (ton) } \\
\end{array}$} & \multicolumn{2}{|c|}{$\begin{array}{c}\text { Bunkering } \\
\text { ports }\end{array}$} & \multicolumn{2}{|c|}{$\begin{array}{c}\text { Bunkered } \\
\text { amount (ton) }\end{array}$} & \multirow{2}{*}{$\begin{array}{c}\text { MDO } \\
\text { consumed } \\
\text { (ton) }\end{array}$} & \multicolumn{2}{|c|}{$\begin{array}{c}\text { Container } \\
\text { loaded }\end{array}$} & \multicolumn{2}{|c|}{$\begin{array}{c}\text { Container } \\
\text { unloaded }\end{array}$} \\
\hline & & & & & & & & $\mathrm{HFO}$ & MDO & HFO & MDO & & $\begin{array}{l}\text { Container } \\
\text { group } 1\end{array}$ & $\begin{array}{l}\text { Container } \\
\text { group } 2\end{array}$ & $\begin{array}{l}\text { Container } \\
\text { group } 1\end{array}$ & $\begin{array}{c}\text { Container } \\
\text { group } 2\end{array}$ \\
\hline $\mathrm{P} 1$ & 10 & 191 & 181 & 1000 & 1000 & 2000 & 1715.1 & - & - & - & - & 284.86 & 322 & 297 & - & - \\
\hline $\mathrm{P} 2$ & 216 & 379 & 163 & 822.6 & 822.6 & 1715.1 & 1055.7 & - & - & - & - & 659.41 & 276 & 281 & - & - \\
\hline P6 & 402 & 509 & 107 & 664.1 & 664.1 & 1055.7 & 403.5 & - & - & - & - & 652.26 & 240 & 281 & - & - \\
\hline P3 & 540 & 707 & 167 & 529.8 & 529.8 & 403.5 & 2000 & - & P3 & - & 2008.1 & 411.54 & 332 & 273 & - & - \\
\hline P5 & 736 & 888 & 152 & 395 & 1000 & 2000 & 1351.9 & P5 & - & 604.99 & & 648.10 & 302 & 246 & - & - \\
\hline $\mathrm{P} 4$ & 915 & 1039 & 124 & 847.2 & 847.2 & 1351.9 & 1084.4 & - & - & - & - & 267.53 & 261 & 262 & - & - \\
\hline P11 & 1080 & 1199 & 119 & 694 & 694 & 1084.4 & 821.9 & - & - & - & - & 262.46 & - & - & 195 & 265 \\
\hline P10 & 1224 & 1332 & 108 & 517.9 & 517.9 & 821.9 & 497.3 & - & - & - & - & 354.54 & - & - & 229 & 214 \\
\hline $\mathrm{P} 12$ & 1356 & 1466 & 110 & 358.6 & 1000 & 467.3 & 64.9 & $\mathrm{P} 12$ & - & 641.42 & - & 402.41 & - & - & 207 & 233 \\
\hline P7 & 1490 & 1598 & 108 & 844.2 & 844.2 & 64.9 & 2000 & - & P7 & - & 2187.7 & 252.62 & - & - & 213 & 241 \\
\hline P8 & 1626 & 1768 & 142 & 706.7 & 706.7 & 2000 & 1639.9 & - & - & - & - & 360.11 & - & - & 197 & 283 \\
\hline P9 & 1801 & 1922 & 121 & 563 & 563 & 1639.9 & 1447.4 & - & - & - & - & 192.49 & - & - & 224 & 258 \\
\hline
\end{tabular}

Table 6: Fuel consumption, vessel speed, travel time and container flow related values for both the ships of the illustrative example

\begin{tabular}{|c|c|c|c|c|c|c|c|c|c|c|c|c|c|}
\hline \multicolumn{7}{|c|}{ Ship 1} & \multicolumn{7}{|c|}{ Ship 2} \\
\hline \multirow{2}{*}{$\begin{array}{c}\text { Each leg } \\
\text { of the } \\
\text { Ship } \\
\text { route }\end{array}$} & \multirow{2}{*}{$\begin{array}{l}\text { Vessel } \\
\text { speed } \\
\text { (knots) }\end{array}$} & \multirow{2}{*}{$\begin{array}{c}\text { Fuel (HFO) } \\
\text { consumption } \\
\text { rate } \\
\text { (ton/day) } \\
\end{array}$} & \multirow{2}{*}{$\begin{array}{l}\text { Fuel (HFO) } \\
\text { consumed } \\
\text { while sailing } \\
\text { (ton) }\end{array}$} & \multirow{2}{*}{$\begin{array}{l}\text { Travel } \\
\text { time } \\
\text { (hour) }\end{array}$} & \multicolumn{2}{|c|}{$\begin{array}{c}\text { Container flowing on } \\
\text { each leg (units) }\end{array}$} & \multirow{2}{*}{$\begin{array}{l}\text { Each leg } \\
\text { of the } \\
\text { Ship route }\end{array}$} & \multirow{2}{*}{$\begin{array}{l}\text { Vessel } \\
\text { speed } \\
\text { (knots) }\end{array}$} & \multirow{2}{*}{$\begin{array}{c}\text { Fuel (HFO) } \\
\text { consumption } \\
\text { rate } \\
\text { (ton/day) } \\
\end{array}$} & \multirow{2}{*}{$\begin{array}{c}\text { Fuel (HFO) } \\
\text { consumed } \\
\text { while } \\
\text { sailing (ton) } \\
\end{array}$} & \multirow{2}{*}{$\begin{array}{l}\text { Travel } \\
\text { time } \\
\text { (hour) }\end{array}$} & \multicolumn{2}{|c|}{$\begin{array}{c}\text { Container flowing on } \\
\text { each leg (units) }\end{array}$} \\
\hline & & & & & $\begin{array}{c}\text { Container } \\
\text { group } 1\end{array}$ & $\begin{array}{l}\text { Container } \\
\text { group } 2 \\
\end{array}$ & & & & & & $\begin{array}{l}\text { Container } \\
\text { group } 1\end{array}$ & $\begin{array}{c}\text { Container } \\
\text { group } 2 \\
\end{array}$ \\
\hline $\mathrm{P} 5-\mathrm{P} 1$ & 20 & 129.77 & 143.56 & 27 & 275 & 296 & $\mathrm{P} 1-\mathrm{P} 2$ & 24 & 172.27 & 177.35 & 25 & 322 & 297 \\
\hline $\mathrm{P} 1-\mathrm{P} 2$ & 21 & 138.97 & 163.51 & 29 & 604 & 545 & $\mathrm{P} 2-\mathrm{P} 6$ & 24 & 172.27 & 158.51 & 23 & 598 & 578 \\
\hline $\mathrm{P} 2-\mathrm{P} 6$ & 22 & 149.09 & 149.66 & 25 & 915 & 871 & $\mathrm{P} 6-\mathrm{P} 3$ & 17 & 107.25 & 134.32 & 31 & 838 & 859 \\
\hline P6 - P4 & 24 & 172.27 & 174.36 & 25 & 1162 & 1154 & $\mathrm{P} 3-\mathrm{P} 5$ & 18 & 113.95 & 134.79 & 29 & 1170 & 1132 \\
\hline $\mathrm{P} 4-\mathrm{P} 3$ & 23 & 160.18 & 168.01 & 26 & 1405 & 1461 & $\mathrm{P} 5-\mathrm{P} 4$ & 21 & 138.97 & 152.76 & 27 & 1472 & 1378 \\
\hline P3-P12 & 24 & 172.27 & 157.31 & 22 & 1706 & 1751 & $\mathrm{P} 4-\mathrm{P} 11$ & 14 & 91.42 & 153.18 & 41 & 1733 & 1640 \\
\hline $\mathrm{P} 12-\mathrm{P} 9$ & 23 & 160.18 & 157.28 & 24 & 1447 & 1505 & $\mathrm{P} 11-\mathrm{P} 10$ & 24 & 172.27 & 176.16 & 25 & 1538 & 1375 \\
\hline $\mathrm{P} 9-\mathrm{P} 11$ & 17 & 107.25 & 145.36 & 33 & 1212 & 1221 & $\mathrm{P} 10-\mathrm{P} 12$ & 23 & 160.18 & 159.31 & 24 & 1309 & 1161 \\
\hline $\mathrm{P} 11-\mathrm{P} 8$ & 15 & 96.02 & 134.43 & 34 & 1010 & 965 & $\mathrm{P} 12-\mathrm{P} 7$ & 23 & 160.18 & 155.82 & 24 & 1102 & 928 \\
\hline $\mathrm{P} 8-\mathrm{P} 7$ & 21 & 138.97 & 162.96 & 29 & 778 & 703 & $\mathrm{P} 7-\mathrm{P} 8$ & 19 & 121.45 & 137.43 & 28 & 889 & 687 \\
\hline P7 - P10 & 20 & 129.77 & 138.42 & 26 & 567 & 472 & P8 - P9 & 17 & 107.25 & 143.78 & 33 & 692 & 404 \\
\hline
\end{tabular}


Table 7: Effect of weather adversities and port closure on vessel route

\begin{tabular}{|c|c|c|c|c|c|c|c|c|c|c|c|c|c|c|c|c|c|}
\hline \multicolumn{6}{|c|}{ Under normal scenario } & \multicolumn{6}{|c|}{ Under Disruption case (weather adversities on route) } & \multicolumn{6}{|c|}{ Under Disruption case (port closure) } \\
\hline \multicolumn{3}{|c|}{ Ship 1} & \multicolumn{3}{|c|}{ Ship 2} & \multicolumn{3}{|c|}{ Ship 1} & \multicolumn{3}{|c|}{ Ship 2} & \multicolumn{3}{|c|}{ Ship 1} & \multicolumn{3}{|c|}{ Ship 2} \\
\hline \multirow{2}{*}{$\begin{array}{l}\text { Port } \\
\text { visit }\end{array}$} & \multicolumn{2}{|c|}{ Bunkering ports } & \multirow{2}{*}{$\begin{array}{l}\text { Port } \\
\text { visit }\end{array}$} & \multicolumn{2}{|c|}{ Bunkering ports } & \multirow{2}{*}{$\begin{array}{l}\text { Port } \\
\text { visit }\end{array}$} & \multicolumn{2}{|c|}{ Bunkering ports } & \multirow{2}{*}{$\begin{array}{l}\text { Port } \\
\text { visit }\end{array}$} & \multicolumn{2}{|c|}{ Bunkering ports } & \multirow{2}{*}{$\begin{array}{l}\text { Port } \\
\text { visit }\end{array}$} & \multicolumn{2}{|c|}{ Bunkering ports } & \multirow{2}{*}{$\begin{array}{l}\text { Port } \\
\text { visit }\end{array}$} & \multicolumn{2}{|c|}{ Bunkering ports } \\
\hline & $\mathrm{HFO}$ & MDO & & $\mathrm{HFO}$ & MDO & & HFO & MDO & & HFO & MDO & & $\mathrm{HFO}$ & MDO & & $\mathrm{HFO}$ & MDO \\
\hline P5 & - & - & $\mathrm{P} 1$ & - & - & P5 & - & - & $\mathrm{P} 1$ & - & - & P5 & - & - & $\mathrm{P} 1$ & - & - \\
\hline $\mathrm{P} 1$ & - & - & $\mathrm{P} 2$ & - & - & $\mathrm{P} 1$ & - & - & P6 & - & - & $\mathrm{P} 1$ & - & - & $\mathrm{P} 2$ & - & - \\
\hline $\mathrm{P} 2$ & - & - & P6 & - & - & P6 & - & - & $\mathrm{P} 2$ & - & - & P6 & - & - & P6 & - & - \\
\hline P6 & - & - & P3 & - & P3 & $\mathrm{P} 2$ & - & $\mathrm{P} 2$ & P3 & - & P3 & $\mathrm{P} 2$ & - & - & P3 & - & - \\
\hline $\mathrm{P} 4$ & $\mathrm{P} 4$ & $\mathrm{P} 4$ & P5 & P5 & - & $\mathrm{P} 4$ & $\mathrm{P} 4$ & - & $\mathrm{P} 4$ & $\mathrm{P} 4$ & - & $\mathrm{P} 4$ & $\mathrm{P} 4$ & $\mathrm{P} 4$ & P5 & P5 & P5 \\
\hline P3 & - & - & $\mathrm{P} 4$ & - & - & P3 & - & - & P5 & - & - & P3 & - & - & $\mathrm{P} 4$ & - & - \\
\hline P12 & - & - & P11 & - & - & P12 & - & - & P11 & - & - & $\mathrm{P} 12$ & - & - & $\mathrm{P} 11$ & - & - \\
\hline P9 & - & - & P10 & - & - & P9 & - & - & P10 & - & - & P9 & - & - & P10 & - & - \\
\hline P11 & P11 & - & P12 & P12 & - & P11 & P11 & - & P12 & P12 & - & P11 & P11 & - & P7 & - & - \\
\hline P8 & - & - & P7 & - & P7 & P7 & - & - & P8 & - & - & P8 & - & - & P12 & P12 & - \\
\hline P7 & - & P7 & P8 & - & - & P8 & - & P8 & P7 & - & P7 & P7 & - & P7 & P8 & - & $\mathrm{P} 8$ \\
\hline $\mathrm{P} 10$ & - & - & P9 & - & - & P10 & - & - & P9 & - & - & P10 & - & - & P9 & - & - \\
\hline \multicolumn{6}{|c|}{ Profit $=$ USD 26,523,252.83 } & \multicolumn{6}{|c|}{ Profit = USD 26,509,507.01 } & \multicolumn{6}{|c|}{ Profit $=$ USD $26,345,865.53$} \\
\hline \multicolumn{6}{|c|}{ Revenue generated = USD 34,051,896 } & \multicolumn{6}{|c|}{ Revenue generated = USD $34,008,422$} & \multicolumn{6}{|c|}{ Revenue generated = USD 34,073,379 } \\
\hline \multicolumn{3}{|c|}{$\begin{array}{l}\text { Bunkering cost for MDO } \\
=\text { USD } 4,653,659.96\end{array}$} & \multicolumn{3}{|c|}{$\begin{array}{c}\text { Carbon tax for } \mathrm{MDO}= \\
\text { USD } 890,944.56\end{array}$} & \multicolumn{3}{|c|}{$\begin{array}{c}\text { Bunkering cost for } \mathrm{MDO}= \\
\text { USD } 4,649,676.64\end{array}$} & $\begin{array}{r}\mathrm{Ca} \\
\mathrm{L} \\
\end{array}$ & $\begin{array}{r}\text { bon } \operatorname{tax} \text { f } \\
= \\
\text { SD } 887,\end{array}$ & $\begin{array}{l}\text { MDO } \\
3.94 \\
\end{array}$ & $\begin{array}{l}\text { Bunke } \\
=\mathrm{U}\end{array}$ & $\begin{array}{l}\text { ing cost } \\
\text { D } 4,577\end{array}$ & $\begin{array}{l}\mathrm{MDO} \\
38.64\end{array}$ & $\begin{array}{r}\text { Carb } \\
\mathrm{U}\end{array}$ & $\begin{array}{l}\text { tax for } \\
\text { D } 880,1\end{array}$ & $\begin{array}{l}\mathrm{IDO}= \\
.66\end{array}$ \\
\hline $\begin{array}{r}\text { Bunk } \\
\mathrm{U} \\
\end{array}$ & $\begin{array}{c}\text { ng cost } \\
= \\
689,26\end{array}$ & $\begin{array}{l}\mathrm{r} \mathrm{HFO} \\
87 \\
\end{array}$ & $\begin{array}{r}\text { Carb } \\
\text { US }\end{array}$ & $\begin{array}{l}\text { n tax fo } \\
\text { D } 305,7\end{array}$ & $\begin{array}{l}\mathrm{IFO}= \\
.75\end{array}$ & $\begin{array}{r}\text { Bunke } \\
\mathrm{L}\end{array}$ & $\begin{array}{l}\text { ing cost } \\
\text { SD } 704,6\end{array}$ & $\begin{array}{l}\text { or } \mathrm{HFO}= \\
9.70\end{array}$ & $\begin{array}{r}\text { Car } \\
\mathrm{L}\end{array}$ & $\begin{array}{l}\text { SD } 308 \\
\text { SD }\end{array}$ & $\begin{array}{l}\mathrm{HFO}= \\
4.69\end{array}$ & $\begin{array}{r}\text { Bunk } \\
=\mathrm{L}\end{array}$ & $\begin{array}{l}\text { ring cost } \\
\text { SD 703, }\end{array}$ & $\begin{array}{l}\text { r HFO } \\
1.20\end{array}$ & $\begin{array}{r}\text { Carb } \\
\mathrm{U}\end{array}$ & $\begin{array}{l}\text { n tax for } \\
\text { D } 306,9\end{array}$ & $\begin{array}{l}\mathrm{IFO}= \\
.95\end{array}$ \\
\hline
\end{tabular}


Table 8: Bunker fuel management strategies for different bunker fuel capacities

\begin{tabular}{|c|c|c|c|c|c|c|c|c|c|c|c|c|c|c|c|c|c|}
\hline \multicolumn{6}{|c|}{ Bunkering capacity (HFO -1000 ton, $\mathrm{MDO}-1000$ ton) } & \multicolumn{6}{|c|}{ Bunkering capacity (HFO -2000 ton, $\mathrm{MDO}-2000$ ton) } & \multicolumn{6}{|c|}{ Bunkering capacity (HFO -3000 ton, $\mathrm{MDO}-3000$ ton) } \\
\hline \multicolumn{3}{|c|}{ Ship 1} & \multicolumn{3}{|c|}{ Ship 2} & \multicolumn{3}{|c|}{ Ship 1} & \multicolumn{3}{|c|}{ Ship 2} & \multicolumn{3}{|c|}{ Ship 1} & \multicolumn{3}{|c|}{ Ship 2} \\
\hline \multirow[t]{2}{*}{$\begin{array}{l}\text { Port } \\
\text { visit }\end{array}$} & \multicolumn{2}{|c|}{$\begin{array}{l}\text { Bunkering ports, } \\
\text { Bunkered amount } \\
\text { (ton) }\end{array}$} & \multirow[t]{2}{*}{$\begin{array}{l}\text { Port } \\
\text { visit }\end{array}$} & \multicolumn{2}{|c|}{$\begin{array}{l}\text { Bunkering ports, } \\
\text { Bunkered amount } \\
\text { (ton) }\end{array}$} & \multirow[t]{2}{*}{$\begin{array}{l}\text { Port } \\
\text { visit }\end{array}$} & \multicolumn{2}{|c|}{$\begin{array}{l}\text { Bunkering ports, } \\
\text { Bunkered amount } \\
\text { (ton) }\end{array}$} & \multirow[t]{2}{*}{$\begin{array}{l}\text { Port } \\
\text { visit }\end{array}$} & \multicolumn{2}{|c|}{$\begin{array}{l}\text { Bunkering ports, } \\
\text { Bunkered amount } \\
\text { (ton) }\end{array}$} & \multirow[t]{2}{*}{$\begin{array}{l}\text { Port } \\
\text { visit }\end{array}$} & \multicolumn{2}{|c|}{$\begin{array}{l}\text { Bunkering ports, } \\
\text { Bunkered amount } \\
\text { (ton) }\end{array}$} & \multirow[t]{2}{*}{$\begin{array}{l}\text { Port } \\
\text { visit }\end{array}$} & \multicolumn{2}{|c|}{$\begin{array}{l}\text { Bunkering ports, } \\
\text { Bunkered amount } \\
\text { (ton) }\end{array}$} \\
\hline & $\mathrm{HFO}$ & MDO & & HFO & MDO & & HFO & MDO & & $\mathrm{HFO}$ & MDO & & $\mathrm{HFO}$ & MDO & & HFO & MDO \\
\hline P5 & - & - & P1 & - & - & P5 & - & - & P1 & - & - & P5 & - & - & P1 & - & - \\
\hline $\mathrm{P} 1$ & - & - & $\mathrm{P} 2$ & - & - & P1 & - & - & $\mathrm{P} 2$ & - & - & P1 & - & - & $\mathrm{P} 2$ & - & - \\
\hline $\mathrm{P} 2$ & - & $\begin{array}{c}\mathrm{P} 2, \\
1358.2\end{array}$ & P6 & - & - & $\mathrm{P} 2$ & - & - & P6 & - & - & $\mathrm{P} 2$ & - & - & P6 & - & - \\
\hline P6 & - & - & P3 & - & $\begin{array}{c}\mathrm{P} 3, \\
1340.3\end{array}$ & P6 & - & - & P3 & - & - & P6 & - & - & P3 & - & - \\
\hline P4 & $\mathrm{P} 4,617.6$ & - & P5 & P5, 623.3 & - & P4 & - & - & P5 & - & P5, 2129.2 & P4 & - & - & P5 & - & - \\
\hline P3 & - & P3, 1074 & $\mathrm{P} 4$ & - & - & P3 & - & $\begin{array}{c}\mathrm{P} 3, \\
2222.1\end{array}$ & P4 & - & - & P3 & - & - & $\mathrm{P} 4$ & - & - \\
\hline P12 & - & - & P11 & - & $\begin{array}{c}\text { P11, } \\
1043.9\end{array}$ & P12 & - & - & $\mathrm{P} 11$ & - & - & P12 & - & $\mathrm{P} 12,3063$ & P11 & - & $\begin{array}{c}\text { P11, } \\
3006.3\end{array}$ \\
\hline P9 & - & - & $\mathrm{P} 10$ & - & - & P9 & $\mathrm{P} 9,1024$ & - & P10 & $\begin{array}{c}\mathrm{P} 10, \\
1020.7\end{array}$ & - & P9 & - & - & P10 & - & - \\
\hline P11 & $\begin{array}{l}\text { P11, } \\
616.2\end{array}$ & - & $\mathrm{P} 12$ & $\mathrm{P} 12,600.5$ & - & P11 & - & - & $\mathrm{P} 12$ & - & - & P11 & - & - & P12 & - & - \\
\hline P7 & - & - & P8 & - & - & P7 & - & - & P8 & - & $\mathrm{P} 8,2340.4$ & P7 & - & - & P8 & - & - \\
\hline P10 & - & - & P9 & - & - & P10 & - & - & P9 & - & - & P10 & - & - & P9 & - & - \\
\hline \multicolumn{6}{|c|}{ Profit = USD 26,450,685.22 } & \multicolumn{6}{|c|}{ Profit $=$ USD 27,374,350.34 } & \multicolumn{6}{|c|}{ Profit $=$ USD $28,897,625.31$} \\
\hline \multicolumn{6}{|c|}{ Revenue generated = USD $34,324,493$} & \multicolumn{6}{|c|}{ Revenue generated = USD $34,379,176$} & \multicolumn{6}{|c|}{ Revenue generated = USD $34,133,412$} \\
\hline \multirow{2}{*}{\multicolumn{6}{|c|}{$\begin{array}{c}\text { Bunkering cost for } \mathrm{MDO}=\mathrm{USD} 3,760,915.01 \\
\text { Carbon tax for } \mathrm{MDO}=821.599 .56 \text { USD }\end{array}$}} & \multirow{2}{*}{\multicolumn{6}{|c|}{$\begin{array}{c}\text { Bunkering cost for } \mathrm{MDO}=\mathrm{USD} 3,398,615.27 \\
\text { Carbon tax for } \mathrm{MDO}=\mathrm{USD} 820,120.20\end{array}$}} & & Bunkeri & $\mathrm{g}$ cost for $\mathrm{M}$ & $\mathrm{O}=\mathrm{U}$ & 2,97 & 3.01 \\
\hline & & & & & & & & & & & & & Carb & $\mathrm{n}$ tax for MI & $\mathrm{O}=\mathrm{US}$ & 827,3 & \\
\hline & Bunkerii & cost for $\mathrm{H}$ & $\mathrm{O}=\mathrm{U}$ & D 625,949.97 & & & Bunkeri & cost for & $\mathrm{FO}=\mathrm{I}$ & D 538,69 & & & & Bunkering $\mathrm{c}$ & st for 1 & $\mathrm{O}=0$ & \\
\hline & Carbol & ax for $\mathrm{HFC}$ & $=\mathrm{USI}$ & $307,161.23$ & & & Carbc & ax for $\mathrm{H}$ & $\mathrm{D}=\mathrm{US}$ & 296,000 & & & Carb & n tax for $\mathrm{HF}$ & $=\mathrm{US}$ & 298,8 & \\
\hline & Fixed & st for bunl & ring $=$ & USD 5,729 & & & Fixec & ost for bu & kering & USD 2,8 & & & & $d \operatorname{cost}$ for bu & kering & USD 1 & \\
\hline
\end{tabular}


Table 9: Bunker fuel management strategies under different bunker prices for both types of fuel

\begin{tabular}{|c|c|c|c|c|c|c|c|c|c|c|}
\hline & \multicolumn{2}{|c|}{ Scenario 1} & \multicolumn{2}{|c|}{ Scenario 2} & \multicolumn{2}{|c|}{ Scenario 3} & \multicolumn{2}{|c|}{ Scenario 4} & \multicolumn{2}{|c|}{ Scenario 5} \\
\hline \multirow{2}{*}{$\begin{array}{l}\text { Ship } 1 \text { (Port } \\
\text { visit) }\end{array}$} & \multicolumn{2}{|c|}{ Bunkered amount (ton) } & \multicolumn{2}{|c|}{ Bunkered amount (ton) } & \multicolumn{2}{|c|}{ Bunkered amount (ton) } & \multicolumn{2}{|c|}{ Bunkered amount (ton) } & \multicolumn{2}{|c|}{ Bunkered amount (ton) } \\
\hline & $\mathrm{HFO}$ & MDO & $\mathrm{HFO}$ & MDO & HFO & MDO & $\mathrm{HFO}$ & MDO & $\mathrm{HFO}$ & MDO \\
\hline Port 5 (P5) & - & - & - & - & - & - & - & - & - & - \\
\hline Port $1(\mathrm{P} 1)$ & - & - & - & - & - & - & - & - & - & - \\
\hline Port $2(\mathrm{P} 2)$ & - & - & - & - & - & - & - & - & - & - \\
\hline Port $6(\mathrm{P} 6)$ & - & P6, 1687 & - & P6, 1595.7 & - & - & - & P6, 1786 & - & - \\
\hline Port $4(\mathrm{P} 4)$ & - & - & - & - & - & $\mathrm{P} 4,1967.7$ & - & - & - & $\mathrm{P} 4,1830.1$ \\
\hline Port 3 (P3) & - & - & P3, 783.07 & - & - & - & - & - & P3, 769.71 & - \\
\hline Port 12 (P12) & P12, 884.83 & - & - & - & P12, 902.90 & - & P12, 898.97 & - & - & - \\
\hline Port 9 (P9) & - & - & - & $\mathrm{P} 9,1582.2$ & - & - & - & - & - & - \\
\hline Port $11(\mathrm{P} 11)$ & - & P11, 1729.9 & - & - & - & - & - & P11, 1797.3 & - & - \\
\hline Port 8 (P8) & - & - & - & - & - & P8, 1683.6 & - & - & - & P8, 1671.1 \\
\hline Port 7 (P7) & - & - & - & - & - & - & - & - & - & - \\
\hline Port $10(\mathrm{P} 10)$ & - & - & - & - & - & - & - & - & - & - \\
\hline \multirow{2}{*}{$\begin{array}{l}\text { Ship } 2 \text { (Port } \\
\text { visit) }\end{array}$} & \multicolumn{2}{|c|}{ Bunkered amounts (tons) } & \multicolumn{2}{|c|}{ Bunkered amounts (tons) } & \multicolumn{2}{|c|}{ Bunkered amounts (tons) } & \multicolumn{2}{|c|}{ Bunkered amounts (tons) } & \multicolumn{2}{|c|}{ Bunkered amounts (tons) } \\
\hline & $\mathrm{HFO}$ & MDO & $\mathrm{HFO}$ & MDO & $\mathrm{HFO}$ & MDO & $\mathrm{HFO}$ & MDO & $\mathrm{HFO}$ & MDO \\
\hline Port $1(\mathrm{P} 1)$ & - & - & - & - & - & - & - & - & - & - \\
\hline Port $2(\mathrm{P} 2)$ & - & - & - & - & - & - & - & - & - & - \\
\hline Port 6 (P6) & - & - & - & P6, 1593.3 & - & - & - & - & - & - \\
\hline Port 3 (P3) & - & - & - & - & - & P3, 1675.4 & - & P3, 1704.6 & - & $\mathrm{P} 3,1510.3$ \\
\hline Port 5 (P5) & - & P5, 1872.3 & - & - & - & - & - & - & - & - \\
\hline Port $4(\mathrm{P} 4)$ & $\mathrm{P} 4,782.54$ & - & $\mathrm{P} 4,778.18$ & - & - & - & - & - & $\mathrm{P} 4,766.49$ & - \\
\hline Port $11(\mathrm{P} 11)$ & - & - & - & P11, 1590.6 & P11, 892.89 & - & $\mathrm{P} 11,887.96$ & - & - & - \\
\hline Port $10(\mathrm{P} 10)$ & - & - & - & - & - & $\mathrm{P} 10,1770.5$ & - & P10, 1646.3 & - & $\mathrm{P} 10,1519$ \\
\hline Port $12(\mathrm{P} 12)$ & - & P12, 1537.3 & - & - & - & - & - & - & - & - \\
\hline Port 7 (P7) & - & - & - & - & - & - & - & - & - & - \\
\hline Port 8 (P8) & P8, 798.40 & - & P8, 763.54 & P8, 1641.7 & - & - & - & - & P8, 756.01 & - \\
\hline Port 9 (P9) & - & - & - & - & - & - & - & - & & - \\
\hline $\begin{array}{c}\text { MDO } \\
\text { Bunkering cost }\end{array}$ & \multicolumn{2}{|c|}{ USD 3,601,151.98 } & \multicolumn{2}{|c|}{ USD 5,335,395.54 } & \multicolumn{2}{|c|}{ USD $2,890,971.74$} & \multicolumn{2}{|c|}{ USD 4,841,861.18 } & \multicolumn{2}{|c|}{ USD $2,741,827.56$} \\
\hline $\begin{array}{c}\text { HFO } \\
\text { Bunkering cost }\end{array}$ & \multicolumn{2}{|c|}{ USD $684,123.17$} & \multicolumn{2}{|c|}{ USD 780,059.06 } & \multicolumn{2}{|c|}{ USD 371,595.04 } & \multicolumn{2}{|c|}{ USD $389,481.25$} & \multicolumn{2}{|c|}{ USD 752,285.98 } \\
\hline Profit & \multicolumn{2}{|c|}{ USD $28,033,655.76$} & USD 26 & $3,106.52$ & USD 30, & $9,426.03$ & USD 27, & $0,970.57$ & USD 30 &, 227.99 \\
\hline
\end{tabular}


Table 10: Sensitivity analysis with respect to Carbon tax and Fuel consumption rate at port

\begin{tabular}{|c|c|c|c|c|c|c|c|c|c|c|c|}
\hline \multicolumn{4}{|c|}{ Scenario 1} & \multicolumn{4}{|c|}{ Scenario 2} & \multicolumn{4}{|c|}{ Scenario 3} \\
\hline \multicolumn{2}{|c|}{ Ship 1} & \multicolumn{2}{|c|}{ Ship 2} & \multicolumn{2}{|c|}{ Ship 1} & \multicolumn{2}{|c|}{ Ship 2} & \multicolumn{2}{|c|}{ Ship 1} & \multicolumn{2}{|c|}{ Ship 2} \\
\hline $\begin{array}{c}\text { MDO } \\
\text { consumed } \\
\text { at each } \\
\text { port (ton) }\end{array}$ & $\begin{array}{c}\text { HFO } \\
\text { consumed } \\
\text { on each leg } \\
\text { (ton) }\end{array}$ & $\begin{array}{c}\text { MDO } \\
\text { consumed } \\
\text { at each } \\
\text { port (ton) }\end{array}$ & $\begin{array}{c}\text { HFO } \\
\text { consumed } \\
\text { on each leg } \\
\text { (ton) }\end{array}$ & $\begin{array}{c}\text { MDO } \\
\text { consumed } \\
\text { at each } \\
\text { port (ton) }\end{array}$ & $\begin{array}{c}\text { HFO } \\
\text { consumed } \\
\text { on each leg } \\
\text { (ton) }\end{array}$ & $\begin{array}{c}\text { MDO } \\
\text { consumed } \\
\text { at each } \\
\text { port (ton) }\end{array}$ & $\begin{array}{c}\text { HFO } \\
\text { consumed } \\
\text { on each leg } \\
\text { (ton) }\end{array}$ & $\begin{array}{c}\text { MDO } \\
\text { consumed } \\
\text { at each } \\
\text { port (ton) }\end{array}$ & $\begin{array}{c}\text { HFO } \\
\text { consumed } \\
\text { on each leg } \\
\text { (ton) }\end{array}$ & $\begin{array}{c}\text { MDO } \\
\text { consumed } \\
\text { at each } \\
\text { port (ton) }\end{array}$ & $\begin{array}{c}\text { HFO } \\
\text { consumed } \\
\text { on each leg } \\
\text { (ton) }\end{array}$ \\
\hline P5, 560 & $\begin{array}{c}\mathrm{P} 5-\mathrm{P} 1 \\
137\end{array}$ & $\mathrm{P} 1,544$ & $\mathrm{P} 1-\mathrm{P} 2,155$ & P5, 306 & $\begin{array}{c}\mathrm{P} 5-\mathrm{P} 1 \\
142\end{array}$ & $\mathrm{P} 1,216$ & $\mathrm{P} 1-\mathrm{P} 2,154$ & P5, 578 & $\begin{array}{c}\mathrm{P} 5-\mathrm{P} 1 \\
143\end{array}$ & $\mathrm{P} 1,343$ & $\begin{array}{c}\mathrm{P} 1-\mathrm{P} 2 \\
154\end{array}$ \\
\hline $\mathrm{P} 1,311$ & $\begin{array}{c}\mathrm{P} 1-\mathrm{P} 2 \\
152\end{array}$ & $\mathrm{P} 2,443$ & $\mathrm{P} 2-\mathrm{P} 6,137$ & $\mathrm{P} 1,197$ & $\begin{array}{c}\mathrm{P} 1-\mathrm{P} 2 \\
154\end{array}$ & $\mathrm{P} 2,197$ & $\mathrm{P} 2-\mathrm{P} 6,135$ & $\mathrm{P} 1,728$ & $\begin{array}{c}\mathrm{P} 1-\mathrm{P} 2 \\
157\end{array}$ & $\mathrm{P} 2,466$ & $\begin{array}{c}\mathrm{P} 2-\mathrm{P} 6 \\
144\end{array}$ \\
\hline $\mathrm{P} 2,568$ & $\begin{array}{c}\mathrm{P} 2-\mathrm{P} 6 \\
135\end{array}$ & P6, 579 & $\mathrm{P} 6-\mathrm{P} 3,142$ & $\mathrm{P} 2,263$ & $\begin{array}{c}\mathrm{P} 2-\mathrm{P} 6 \\
135\end{array}$ & P6, 227 & $\mathrm{P} 6-\mathrm{P} 3,138$ & $\mathrm{P} 2,1036$ & $\begin{array}{c}\mathrm{P} 2-\mathrm{P} 6 \\
142\end{array}$ & P6, 700 & $\begin{array}{c}\text { P6-P3, } \\
147\end{array}$ \\
\hline P6, 429 & $\begin{array}{c}\mathrm{P} 6-\mathrm{P} 4 \\
151\end{array}$ & P3, 246 & P3 - P5, 163 & P6, 295 & $\begin{array}{c}\mathrm{P} 6-\mathrm{P} 4 \\
149\end{array}$ & P3, 224 & P3 - P5, 148 & P6, 697 & $\begin{array}{c}\mathrm{P} 6-\mathrm{P} 4 \\
145\end{array}$ & P3, 942 & $\begin{array}{c}\text { P3 - P5 } \\
137\end{array}$ \\
\hline $\mathrm{P} 4,424$ & $\begin{array}{c}\mathrm{P} 4-\mathrm{P} 3, \\
136\end{array}$ & P5, 395 & $\mathrm{P} 5-\mathrm{P} 4,137$ & $\mathrm{P} 4,131$ & $\begin{array}{c}\mathrm{P} 4-\mathrm{P} 3, \\
146\end{array}$ & P5, 145 & $\mathrm{P} 5-\mathrm{P} 4,135$ & $\mathrm{P} 4,778$ & $\begin{array}{c}\mathrm{P} 4-\mathrm{P} 3 \\
134\end{array}$ & P5, 791 & $\begin{array}{c}\mathrm{P} 5-\mathrm{P} 4 \\
157\end{array}$ \\
\hline P3, 237 & $\begin{array}{c}\mathrm{P} 3-\mathrm{P} 12 \\
144\end{array}$ & $\mathrm{P} 4,476$ & $\begin{array}{c}\text { P4-P11, } \\
139\end{array}$ & P3, 248 & $\begin{array}{c}\mathrm{P} 3-\mathrm{P} 12 \\
135\end{array}$ & $\mathrm{P} 4,193$ & $\begin{array}{c}\mathrm{P} 4-\mathrm{P} 11, \\
156\end{array}$ & $\mathrm{P} 3,450$ & $\begin{array}{c}\mathrm{P} 3-\mathrm{P} 12 \\
157\end{array}$ & P4, 598 & $\begin{array}{c}\mathrm{P} 4-\mathrm{P} 11, \\
157\end{array}$ \\
\hline $\mathrm{P} 12,300$ & $\begin{array}{c}\mathrm{P} 12-\mathrm{P} 9, \\
159\end{array}$ & $\mathrm{P} 11,418$ & $\begin{array}{c}\text { P11-P10, } \\
144\end{array}$ & $\mathrm{P} 12,151$ & $\begin{array}{c}\mathrm{P} 12-\mathrm{P} 9 \\
152\end{array}$ & $\mathrm{P} 11,119$ & $\begin{array}{c}\mathrm{P} 11-\mathrm{P} 10 \\
153\end{array}$ & $\mathrm{P} 12,275$ & $\begin{array}{c}\mathrm{P} 12-\mathrm{P} 9 \\
148\end{array}$ & $\mathrm{P} 11,847$ & $\begin{array}{c}\mathrm{P} 11-\mathrm{P} 10 \\
150\end{array}$ \\
\hline P9, 297 & $\begin{array}{c}\text { P9-P11, } \\
140\end{array}$ & $\mathrm{P} 10,300$ & $\begin{array}{c}\mathrm{P} 10-\mathrm{P} 12, \\
152\end{array}$ & P9, 169 & $\begin{array}{c}\mathrm{P} 9-\mathrm{P} 11, \\
131\end{array}$ & $\mathrm{P} 10,251$ & $\begin{array}{c}\mathrm{P} 10-\mathrm{P} 12 \\
157\end{array}$ & P9, 477 & $\begin{array}{c}\mathrm{P} 9-\mathrm{P} 11, \\
153\end{array}$ & $\mathrm{P} 10,610$ & $\begin{array}{c}\mathrm{P} 10-\mathrm{P} 12 \\
140\end{array}$ \\
\hline $\mathrm{P} 11,263$ & $\begin{array}{c}\text { P11-P8, } \\
151\end{array}$ & P12, 396 & $\begin{array}{c}\text { P12-P7, } \\
148\end{array}$ & $\mathrm{P} 11,184$ & $\begin{array}{c}\text { P11- P8, } \\
136\end{array}$ & P12, 168 & $\begin{array}{c}\text { P12-P7, } \\
142\end{array}$ & $\mathrm{P} 11,639$ & $\begin{array}{c}\text { P11- P8, } \\
152\end{array}$ & P12, 299 & $\begin{array}{c}\mathrm{P} 12-\mathrm{P} 7 \\
137\end{array}$ \\
\hline P8, 233 & $\begin{array}{c}\mathrm{P} 8-\mathrm{P} 7 \\
146\end{array}$ & P7, 325 & P7 - P8, 141 & P8, 176 & $\begin{array}{c}\mathrm{P} 8-\mathrm{P} 7 \\
147\end{array}$ & P7, 277 & $\mathrm{P} 7-\mathrm{P} 8,133$ & $\mathrm{P} 8,553$ & $\begin{array}{c}\mathrm{P} 8-\mathrm{P} 7 \\
135\end{array}$ & P7, 427 & $\begin{array}{c}\mathrm{P} 7-\mathrm{P} 8 \\
152\end{array}$ \\
\hline $\mathrm{P} 7,372$ & $\begin{array}{c}\mathrm{P} 7-\mathrm{P} 10, \\
146\end{array}$ & P8, 385 & P8 - P9, 157 & P7, 263 & $\begin{array}{c}\mathrm{P} 7-\mathrm{P} 10 \\
138\end{array}$ & P8, 105 & P8 - P9, 147 & P7, 448 & $\begin{array}{c}\mathrm{P} 7-\mathrm{P} 10, \\
150\end{array}$ & P8, 340 & $\begin{array}{c}\text { P8 - P9, } \\
147\end{array}$ \\
\hline $\mathrm{P} 10,320$ & & P9, 217 & & P10, 305 & & P9, 165 & & P10, 777 & & P9, 590 & \\
\hline \multicolumn{4}{|c|}{ Carbon Tax associated with MDO = USD 840,184.02 } & \multicolumn{4}{|c|}{ Carbon Tax associated with MDO $=$ USD 231,150 } & \multicolumn{4}{|c|}{$\begin{array}{c}\text { Carbon Tax associated with MDO }=\text { USD } \\
2,004,625.26\end{array}$} \\
\hline \multicolumn{4}{|c|}{ Carbon Tax associated with HFO = USD 291,530.70 } & \multicolumn{4}{|c|}{ Carbon Tax associated with HFO = USD 143,800.69 } & \multicolumn{4}{|c|}{ Carbon Tax associated with HFO = USD 441,886.39 } \\
\hline \multicolumn{4}{|c|}{ Profit $=$ USD $28,867,713.55$} & \multicolumn{4}{|c|}{ Profit $=$ USD 31,511,561.99 } & \multicolumn{4}{|c|}{ Profit $=$ USD $25,363,466.55$} \\
\hline
\end{tabular}


Table 11: Ship routes, vessel speed and bunkering decisions of some of the problem instances

\begin{tabular}{|c|c|c|c|c|c|}
\hline Problem size & $\begin{array}{l}\text { Ship } \\
\text { no. }\end{array}$ & $\begin{array}{c}\text { Route of the ships } \\
\text { (ports visited by the ship) }\end{array}$ & $\begin{array}{l}\text { Bunkering ports for marine diesel } \\
\text { oil and bunkered amounts (ton) }\end{array}$ & $\begin{array}{l}\text { Bunkering ports for heavy fuel oil } \\
\text { and bunkered amounts (ton) }\end{array}$ & Vessel speed on each leg (knots) \\
\hline \multirow{6}{*}{$\begin{array}{c}(10,10,25,2,6, \\
2) \\
\text { (supply ports, } \\
\text { demand ports, } \\
\text { periods, } \\
\text { containers, } \\
\text { ships, fuel } \\
\text { types) }\end{array}$} & Ship 1 & $\begin{array}{c}8,9,1,5,10,2,3,6,7,4,14,19,13,20 \\
17,16,15,18,11,12\end{array}$ & P6 - 2092.9; P18 - 2258.6; & $\begin{array}{l}\mathrm{P} 10-637.8 ; \mathrm{P} 7-569 ; \mathrm{P} 13- \\
\quad 621.5 ; \mathrm{P} 15-579.8\end{array}$ & $\begin{array}{c}22,24,23,18,16,22,14,23,22,22,23,16, \\
20,17,20,19,21,24,16\end{array}$ \\
\hline & Ship 2 & $\begin{array}{c}6,9,7,4,3,1,5,2,10,8,19,20,18,12 \\
11,16,13,14,15,17\end{array}$ & P5-2081; P16-2050 & $\begin{array}{l}\mathrm{P} 3-585.8 ; \mathrm{P} 10-629.3 ; \mathrm{P} 18- \\
\quad 634.2 ; \mathrm{P} 13-565.7\end{array}$ & $\begin{array}{c}18,19,24,20,23,19,21,22,16,14,23,23, \\
16,17,15,15,18,23,20\end{array}$ \\
\hline & Ship 3 & $\begin{array}{c}5,7,6,2,1,4,9,3,8,10,16,15,19,13 \\
18,17,14,11,12,20\end{array}$ & P3 - 2223.7; P18- 2039.6 & $\begin{array}{l}\mathrm{P} 1-607.4 ; \mathrm{P} 8-618.3 ; \mathrm{P} 19- \\
\text { 598.8; P14-603.5 }\end{array}$ & $\begin{array}{c}15,20,24,20,21,21,20,22,21,21,21,17 \\
16,22,24,15,21,20,17\end{array}$ \\
\hline & Ship 4 & $\begin{array}{c}8,4,9,2,1,3,7,10,5,6,17,15,14,16 \\
19,20,12,11,13,18\end{array}$ & P10-2035.3; P12-2206.8 & $\begin{array}{c}\text { P1 - 600.3; P5-606.3; P14- } \\
\text { 597.7; P12-619.5 }\end{array}$ & $\begin{array}{c}16,15,20,14,22,24,21,20,22,22,18,19, \\
15,18,15,20,15,23,14\end{array}$ \\
\hline & Ship 5 & $\begin{array}{c}5,3,9,1,6,7,10,8,4,2,17,20,19,15 \\
13,12,14,18,11,16\end{array}$ & P10 - 2140; P12-2205.2 & $\begin{array}{l}\mathrm{P} 6-607 ; \mathrm{P} 4-601.8 ; \mathrm{P} 19- \\
598.5 ; \mathrm{P} 14-559.8\end{array}$ & $\begin{array}{c}19,17,14,24,19,15,15,21,22,20,20,14 \\
17,15,19,18,24,17,16\end{array}$ \\
\hline & Ship 6 & $\begin{array}{c}5,4,10,8,7,6,3,9,2,1,18,16,13,15 \\
11,19,14,17,12,20\end{array}$ & P9-2203; P19-2093.8 & $\begin{array}{c}\mathrm{P} 7-619.7 ; \mathrm{P} 2-629.6 ; \mathrm{P} 13- \\
585.2 ; \mathrm{P} 14-580.9\end{array}$ & $\begin{array}{c}18,17,24,22,24,19,23,23,21,15,15,22, \\
16,15,16,24,19,15,24\end{array}$ \\
\hline \multirow{8}{*}{$\begin{array}{c}(12,12,30,2,8, \\
2) \\
\text { (supply ports, } \\
\text { demand ports, } \\
\text { periods, } \\
\text { containers, } \\
\text { ships, fuel } \\
\text { types) }\end{array}$} & Ship 1 & $\begin{array}{c}7,12,3,1,8,4,6,9,10,5,11,2,24,17 \\
18,13,21,23,15,20,16,19,14,22\end{array}$ & $\begin{array}{c}\mathrm{P} 4-2226.3 ; \mathrm{P} 11-2302.7 ; \mathrm{P} 21- \\
\text { 2306.2; P14-2319.1 }\end{array}$ & $\begin{array}{l}\mathrm{P} 8-609.2 ; \mathrm{P} 10-633.4 ; \mathrm{P} 24- \\
594.1 ; \mathrm{P} 21-626.6 ; \mathrm{P} 16-565.1\end{array}$ & $\begin{array}{c}18,15,21,16,20,21,19,15,16,18,18,20 \\
23,15,22,14,16,16,14,14,20,17,15\end{array}$ \\
\hline & Ship 2 & $\begin{array}{c}3,12,11,7,5,10,2,6,9,1,8,4,19,13 \\
21,14,15,24,22,17,18,20,16,23\end{array}$ & $\begin{array}{c}\text { P5 - 2346.5; P9-2160.6; P21 - } \\
\text { 2254.2; P20 - 2355.8 }\end{array}$ & $\begin{array}{c}\text { P5 - 593.1; P9- 592.7; P19- } \\
593.5 ; \mathrm{P} 15-580.2 ; \mathrm{P} 18-597.9\end{array}$ & $\begin{array}{c}19,22,19,24,17,21,19,17,23,14,15,17 \\
19,21,18,14,14,16,16,21,15,19,18\end{array}$ \\
\hline & Ship 3 & $\begin{array}{c}9,3,5,11,6,7,12,2,10,4,1,8,24,13 \\
17,16,18,15,23,21,19,20,22,14\end{array}$ & $\begin{array}{c}\mathrm{P} 7-2743.9 ; \mathrm{P} 8-2341.5 ; \mathrm{P} 23- \\
2394.9\end{array}$ & $\begin{array}{c}\mathrm{P} 6-609.2 ; \mathrm{P} 10-583.8 ; \mathrm{P} 24- \\
659 ; \mathrm{P} 18-616.4 ; \mathrm{P} 19-587.5\end{array}$ & $\begin{array}{c}23,21,20,14,15,22,21,18,24,14,24,21, \\
21,24,20,19,18,23,19,17,20,16,20\end{array}$ \\
\hline & Ship 4 & $\begin{array}{c}12,9,10,8,1,3,7,2,6,11,4,5,18,14 \\
13,17,23,20,21,19,15,24,22,16\end{array}$ & $\begin{array}{c}\mathrm{P} 1-2208.3 ; \mathrm{P} 11-2351.4 ; \mathrm{P} 23- \\
\text { 2037.5; P22 - 2175.7 }\end{array}$ & $\begin{array}{c}\mathrm{P} 1-608.9 ; \mathrm{P} 6-605.6 ; \mathrm{P} 18- \\
614.8 ; \mathrm{P} 23-597.8 ; \mathrm{P} 15-575.1\end{array}$ & $\begin{array}{c}18,14,17,14,22,23,21,14,20,24,20,15 \\
18,24,22,17,23,19,17,18,20,22,17\end{array}$ \\
\hline & Ship 5 & $\begin{array}{c}5,4,11,2,7,12,6,8,10,3,9,1,19,17 \\
15,22,18,20,14,21,13,16,24,23\end{array}$ & $\begin{array}{c}\mathrm{P} 2-2051.7 ; \mathrm{P} 10-2417.8 ; \mathrm{P} 15- \\
\text { 2262.8; P13-2188.2 }\end{array}$ & $\begin{array}{l}\text { P7 - 584.7; P10-621.9; P19- } \\
587.7 ; \mathrm{P} 18-607.6 ; \mathrm{P} 13-603.9\end{array}$ & $\begin{array}{c}23,15,17,14,14,16,24,20,14,24,20,22, \\
18,17,20,21,17,17,24,18,22,21,18\end{array}$ \\
\hline & Ship 6 & $\begin{array}{c}7,2,10,4,3,1,11,12,6,9,8,5,13,22 \\
24,21,17,18,23,14,15,19,20,16\end{array}$ & $\begin{array}{l}\mathrm{P} 4-2145.3 ; \mathrm{P} 6-2034.4 ; \mathrm{P} 22- \\
\quad 2141.7 ; \mathrm{P} 15-2264.8\end{array}$ & $\begin{array}{c}\mathrm{P} 3-594.5 ; \mathrm{P} 6-602.5 ; \mathrm{P} 13- \\
599.1 ; \mathrm{P} 17-595.3 ; \mathrm{P} 15-607.5\end{array}$ & $\begin{array}{c}21,19,17,21,21,16,20,22,14,21,16,17 \\
24,16,22,18,18,21,23,24,18,21,20\end{array}$ \\
\hline & Ship 7 & $\begin{array}{c}4,5,2,1,7,3,11,9,10,6,8,12,23,21 \\
16,24,17,18,22,20,15,19,13,14\end{array}$ & $\begin{array}{c}\text { P7 - 2140.8; P6- 2441.1; P24- } \\
\text { 2002.5; P13-2100.2 }\end{array}$ & $\begin{array}{l}\text { P7 - 624.6; P10-611.7; P23- } \\
\text { 603.6; P17-607.1, P15-593.9 }\end{array}$ & $\begin{array}{c}15,23,23,15,21,22,16,16,23,16,15,22, \\
23,14,22,15,20,16,16,21,16,24,17\end{array}$ \\
\hline & Ship 8 & $\begin{array}{c}1,8,12,4,9,7,3,2,5,6,11,10,16,13 \\
24,14,18,20,21,19,23,22,15,17\end{array}$ & $\begin{array}{c}\mathrm{P} 7-2552.6 ; \mathrm{P} 10-2366.4 ; \mathrm{P} 21- \\
2155 ;\end{array}$ & $\begin{array}{c}\mathrm{P} 9-630.9 ; \mathrm{P} 5-603.8 ; \mathrm{P} 16- \\
600.4 ; \mathrm{P} 18-624.5 ; \mathrm{P} 23-572.8\end{array}$ & $\begin{array}{c}20,24,21,21,17,14,18,21,18,14,21,23, \\
24,24,22,22,20,18,15,17,22,18,24\end{array}$ \\
\hline
\end{tabular}

